National Library

of Canada

Acquisitions and

Bibliographic Services Branch

395 Wellington Street

Ottawa. Onlario

K1A ON4
Bibliotheque nationale du Canada

Direction des acquisitions et des services bibliographiques

395 , we Wellington

Oltawa (Ontario) rour the vistocterermie

Qu the Nolre talerence
NOTICE
AVIS
The quality of this microform is heavily dependent upon the quality of the original thesis submitted for microfilming. Every effort has been made to ensure the highest quality of reproduction possible.

If pages are missing, contact the university which granted the degree.

Some pages may have indistinct print especially if the original pages were typed with a poor typewriter ribbon or if the university sent us an inferior photocopy.

Reproduction in full or in part of this microform is governed by the Canadian Copyright Act, R.S.C. 1970, c. C-30, and subsequent amendments.
La qualité de cette microforme dépend grandement de la qualité de la thèse soumise au microfilmage. Nous avons tout fait pour assurer une qualité supérieure de reproduction.

S'il manque des pages, veuillez communiquer avec l'université qui a conféré le grade.

La qualité d'impression de certaines pages peut laisser à désirer, surtout si les pages originales ont été dactylographiées à l'aide d'un ruban usé ou si l'université nous a fait parvenir une photocopie de qualité inférieure.

La reproduction, même partielle, de cette microforme est soumise à la Loi canadienne sur le droit d'auteur, SRC 1970, c. C-30, et ses amendements subséquents. 


\title{
Enhancement of Superconductivity in Relaxed Fe-Zr Metallic Glasses
}

by

\author{
Mohsen Sabouri-Ghomi \\ Center for the Physics of Materials \\ Department of Physics, McGill University \\ Montreal, Canada
}

December 1994

\begin{abstract}
A Thesis submitted to the
Faculty of Graduate Studies and Research

in partial fulfillment of the requirements for the degree of Master of Science
\end{abstract}

(C)Mohsen Sabouri-Ghomi, 1994 
National Library

of Canada

Acquisitions and

Bibliographic Services Branch

395 Wellinglon Street

Ottawa, Ontario

KIA ON4
Bibliotheque nationale

du Canada

Direction des acquisitions et

des services bibliographiques

395. no Wellington

Ottawa (Ontario)

K1AON4
THE AUTHOR HAS GRANTED AN IRREVOCABLE NON-EXCLUSIVE LICENCE ALLOWING THE NATIONAL LIBRARY OF CANADA TO REPRODUCE, LOAN, DISTRIBUTE OR SELL COPIES OF HIS/HER THESIS BY ANY MEANS AND IN ANY FORM OR FORMAT, MAKING THIS THESIS AVAILABLE TO INTERESTED PERSONS.

THE AUTHOR RETAINS OWNERSHIP OF THE COPYRIGHT IN HIS/HER THESIS. NEITHER THE THESIS NOR SUBSTANTIAL EXTRACTS FROM IT MAY BE PRINTED OR OTHERWISE REPRODUCED WITHOUT HIS/HER PERMISSION.
L'AUTEUR A ACCORDE UNE LICENCE IRREVOCABLE ET NON EXCLUSIVE PERMETTANT A LA BIBLIOTHEQUE NATIONALE DU CANADA DE REPRODUIRE, PRETER, DISTRIBUER OU VENDRE DES COPIES DE SA THESE DE QUELQUE MANIERE ET SOUS QUELQUE FORME QUE CE SOIT POUR METTRE DES EXEMPLAIRES DE CETTE THESE A LA DISPOSITION DES PERSONNE INTERESSEES.

L'AUTEUR CONSERVE LA PROPRIETE DU DROIT D'AUTEUR QUI PROTEGE SA THESE. NI LA THESE NI DES EXTRAITS SUBSTANTIELS DE CELLECI NE DOIVENT ETRE IMPRIMES OU AUTREMENT REPRODUITS SANS SON AUTORISATION. 


\begin{abstract}
This thesis presents the effects of the irreversible structural relaxation on the superconducting transition temperature, $\mathrm{T}_{c}$, for $\mathrm{Fe}_{x} \mathrm{Zr}_{100-x}$ metallic glasses in the range $20 \leq x \leq 33$. Quality of all fourteen samples prepared by melt spinning technique were examined using X-ray diffractometry and differential scanning calorimetry. Magnetic susceptibility, upper critical field, and superconducting transition temperature were measured for as-made and relaxed $\mathrm{Zr}$-rich compositions. The results showed an unusual increase in superconducting transition temperature upon thermal annealing which was not observed previously in any other metallic glass systems. This phenomenon is due to the presence of spin fluctuations in Fe-Zr glasses. Upon structural relaxation the decrease in the electron-phonon coupling constant, $\lambda_{\mathrm{ep}}$, leads to a decrease in $\mathrm{T}_{c}$ for all superconducting metallic glasses. However, it is shown that when spin fluctuations are present, the decrease in spin fluctuations mass enhancement parameter, $\lambda_{\text {sf }}$, upon relaxation is responsible for the overall enhancement in $T_{c} . A$ theoretical basis for this $T_{c}$ enhancement is provided by analyzing the experimental data using the modified form of the McMillan equation and the Ginsburg-LandauGor'kov expression for the upper critical field together with the expression for the Stoner enhanced magnetic susceptibility.
\end{abstract}




\section{Résumé}

Cette thèse présente les effets de la relaxation structurelle irréversible sur la température critique de transition supraconductrice, $\mathrm{T}_{c}$, pour les verres métalliques $\mathrm{Fe}_{\mathrm{x}} \mathrm{Zr}_{\mathrm{r}_{100-x}}$ dans l'intervalle $20 \leq x \leq 33$. La qualité des quatorze échantillons préparćs par solidification rapide sur tambour rotatif a été examinée par diffraction de rayons $\mathrm{X}$ et calorimétrie différentielle à balayage. La susceptibilité magnétique, le champ critique supérieur ainsi que la température critique de transition supraconductrice ont été mesurés pour les échantillons riches en zirconium, tels que fabriqués ou après relaxation. Les résultats montrent un accroissement inhabituel de $\mathrm{T}_{\mathrm{c}}$ lors $\mathrm{du}$ recuit thermique, ce qui n'a été observé auparavant dans aucun autre verre métallique. Ce phénomène est dû à la présence de fluctuations de spin dans les verres Fe-Zr. Lors de la relaxation structurelle, la diminution de la constante de couplage électron-phonon, $\lambda_{e p}$, conduit à la diminution de $\mathrm{T}_{\mathrm{c}}$ pour tous les verres métalliques supraconducteurs. Cependant, il est montré que lorsque les fluctuations de spin sont présentes, la diminution du paramètre de fluctuations de spin, $\lambda_{\rho f}$, lors de la relaxation est responsable de l'accroissement global de $\mathrm{T}_{\mathrm{c}}$. Une base théorique de cet accroissement de $\mathrm{T}_{\mathrm{c}}$ est fournie en analysant les données expérimentales et en utilisant la forme modifiée de l'équation de McMillan et l'expression de Ginsburg-Landau-Gor'kov pour le champ critique supérieur ainsi que l'expression pour la susceptibilité magnétique renforcée de Stoner. 


\section{Acknowledgments}

I would like to take this opportunity to thank my supervisor Prof. Zaven Altounian for all the support he gave me throughout my degree. I want him to know that I greatly appreciated his constant encouragement and his patience, especially during the writing of the thesis.

I am very greatful to Dr. Ming Mao for the time he spent initiating me to the experimental techniques used in sample preparation and characterization and also for his help in susceptibility measurements at McMaster University. I would like to thank Dr. Andrew Dawson for useful discussions during the sample preparation. I am greatful to Stephane Legault, who helped me with sample mounting and making the special electrical contacts needed for dilution fridge measurements, and also to Benoit lussier who helped me with dilution fridge measurements. I appreciate greatly the help I received from Dr. Xiaoping Bian, Dr. Ralf Brüning and Eric Dufresne with UNIX and with the fitting routine I used for the analysis of the data in this thesis. I owe many thanks to Zhida Yan who patiently helped me whenever I got stuck with ${ }_{\mathrm{AA}} \mathrm{E} \mathrm{X}$. A special thank is given to Karim Aguenaou who spared time from his tight schedule to translate the abstract to French.

This work was made possible by a scholarship from the Ministry of Culture and Higher Education of the Islamic Republic of Iran. This financial support is greatly appreciated.

I would like to thank my loving parents, who have supported me throughout the years. Finally I would like to thank my wife, for her moral support, encouragement and understanding. 


\section{Contents}

Abstract $\quad$ i

Résumé $\quad$ ii

Acknowledgements

List of Figures vi

List of Tables vii

1 Introduction 1

2 Experimental Methods 5

2.1 Sample Preparation . . . . . . . . . . . . . 5

2.2 Characterization ................ 6

2.2.1 X-ray Diffraction . . . . . . . . . . . . . 6

2.2.2 Differential Scanning Calorimetry (DSC) . . . . . . . 10

2.2.3 Electron Beam Microprobe Measurements . . . . . . . 10

2.3 Density Measurements . . . . . . . . . . . . . . . . 11

2.4 Room Temperature Resistivity Measurements . . . . . . . . . 13

2.5 Annealing Technique . . . . . . . . . . . . . . 13

2.6 SQUID Measurements . . . . . . . . . . . . . . 14

2.7 Dilution Fridge Measurements . . . . . . . . . . . . 15

3 Results and Discussions 23

3.1 Superconductivity In Amorphous Metallic Alloys: Theoretical Back-

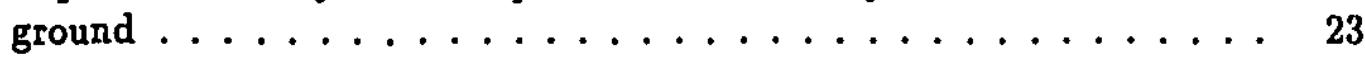

3.2 DSC Measurements Results . . . . . . . . . . . . . 28

3.3 Room temperature resistivity measurements results . . . . . . . 33

3.4 SQUID Measurements Results . . . . . . . . . . . . . . 36

3.4.1 $\mathrm{T}_{\mathrm{c}}$ Measurements Results . . . . . . . . . . 36

3.4.2 Susceptibility Measurements results . . . . . . . . . 38

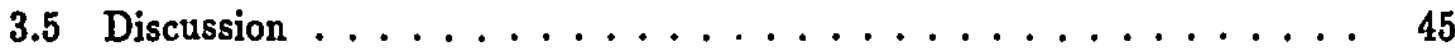

4 Conclusions $\quad 49$ 


\section{List of Figures}

1.1 Schematic illustration of the change in volume with temperature as a supercooled liquid is cooled through the glass transition temperature $T_{g}$. The first-order phase transition, at $T_{f}$, corresponding to the crystallization from the melt is also shown. The small vertical arrow illustrates the volume change accompanying the structural relaxation. $\mathrm{T}_{\mathrm{b}}$ is the boiling temperature. (reproduced from ref. [1]) . . . . 2

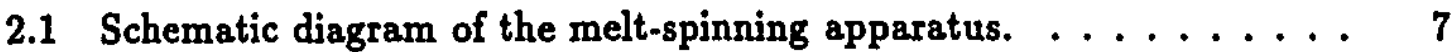

2.2 A schematic drawing of the X-ray diffractometer. . . . . . . 8

2.3 X-ray diffraction pattern, showing the amorphous nature of $\mathrm{Fe}_{33} \mathrm{Z}_{\mathbf{5 7 7}} . \quad 9$

2.4 A schematic diagram of the dilution fridge set up $\ldots \ldots \ldots \ldots 17$

$2.5 \mathrm{~T}_{\mathrm{c}}$ curve for relaxed $\mathrm{Fe}_{30} \mathrm{Z}_{\mathrm{r}_{70}}$ at $\mathrm{T}=0.140 \mathrm{~K} \ldots \ldots \ldots \ldots$

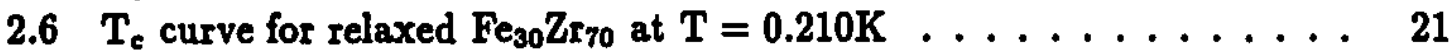

$2.7 \mathrm{~T}_{\mathrm{c}}$ curve for relaxed $\mathrm{Fe}_{30} \mathrm{Z}_{\mathrm{r} 70}$ at $\mathrm{T}=0.230 \mathrm{~K} \ldots \ldots \ldots \ldots \ldots \ldots$

3.1 DSC thermographs for samples $\mathrm{Fe}_{33} \mathrm{Z}_{\mathrm{r}_{67}}$ to $\mathrm{Fe}_{29} \mathrm{Z}_{\mathrm{r}_{71}} \ldots \ldots \ldots \ldots \ldots$

3.2 DSC thermographs for samples $\mathrm{Fe}_{28} \mathrm{Z}_{72}$ to $\mathrm{Fe}_{24} \mathrm{Zr}_{78} \ldots \ldots \ldots \ldots \ldots$

3.3 DSC thermographs for samples $\mathrm{Fe}_{23} \mathrm{Z}_{77}$ to $\mathrm{Fe}_{20} \mathrm{Z}_{\mathrm{r}_{80}} \ldots \ldots \ldots \ldots \ldots \ldots$

3.4 Crystallization temperature $\left(\mathrm{T}_{\mathrm{x}}\right)$ vs. composition . . . . . . . 32

3.5 Room temperature resistivity vs. composition . . . . . . . . 35

3.6 Zero field superconducting transition temperature, $T_{c}$, vs. composition 40

3.7 $M$ vs. $H$ for as-made ad relaxed $\mathrm{Fe}_{30} \mathrm{Zr}_{70}$. $\mathrm{M}$ is mass normalized. . . . 41

3.8 $\mathrm{M}$ v8. $\mathrm{H}$ for as-made ad relaxed $\mathrm{Fe}_{24} \mathrm{Z}_{\mathrm{r}_{78} .} \mathrm{M}$ is mass normalized. . . . 42

$3.9 \mathrm{M}$ v8. $\mathrm{H}$ for as-made ad relaxed $\mathrm{Fe}_{20} \mathrm{Zr}_{80} . \mathrm{M}$ is mass normalized. . . . 43

3.10 Variation of $\chi_{v}$ with composition $\ldots \ldots \ldots \ldots \ldots \ldots$

$3.11 \mathrm{~T}_{\mathrm{e}}$ vs. $\lambda_{\mathrm{ep}} \ldots \ldots \ldots \ldots \ldots \ldots \ldots \ldots \ldots \ldots \ldots \ldots$

$3.12 \mathrm{~T}_{\mathrm{c}}$ vs. $\lambda_{\mathrm{sf}} \ldots \ldots \ldots \ldots \ldots \ldots \ldots \ldots \ldots \ldots \ldots \ldots$ 


\section{List of Tables}

2.1 Electron microprobe results $\ldots \ldots \ldots \ldots \ldots \ldots \ldots \ldots$

2.2 Density measurements results $\ldots \ldots \ldots \ldots \ldots \ldots \ldots \ldots$

3.1 Room temperature resistivity measurements results $\ldots \ldots \ldots \ldots 34$

$3.2 \mathrm{~T}_{\mathrm{c}}$ measurement results at Zero magnetic field $\ldots \ldots \ldots \ldots \ldots$

3.3 Measured values of $\left.\frac{\mathrm{dH}_{\mathrm{s}}}{\mathrm{dT}}\right|_{\mathrm{Tc}}(\mathrm{kOe} / \mathrm{K}) \ldots \ldots \ldots \ldots \ldots \ldots \ldots$

3.4 Valence susceptibility, $\chi_{v} \ldots \ldots \ldots \ldots \ldots \ldots \ldots \ldots \ldots$

3.5 Calculated values of $\overline{\mathrm{I}}$ and $\lambda_{\text {sf }} \ldots \ldots \ldots \ldots \ldots \ldots$ 


\section{Chapter 1}

\section{Introduction}

Metallic glasses or amorphous metallic alloys are metallic alloys which do not have the long range translational order (periodicity), characteristic of a crystal. They are made by a variety of techniques like thermal evaporation, sputtering, glow-discharge decomposition, chemical vapour deposition, and most important, melt-quenching. All these techniques are based on rapid solidification of the alloys from the gas or liquid phases such that the atoms become frozen in their "random" configurations. The term "metallic glass" is usually used for those amorphous metallic alloys which are produced by melt-quenching techniques. In this technique which was used to produce amorphous ribbons of Iron-Zirconium for the present work, a jet of hot molten metallic alloy is propelled against the surface of a rapidly rotating copper disc at room temperature. This process solidifies the liquid metal into a thin ribbon form. Since the created ribbon is very thin and it is in contact with a large heat sink of high thermal conductivity, the liquid cools and solidifies extremely fast. Very high cooling rates of about $10^{6} \mathrm{~K} / \mathrm{sec}$, necessary for undercooling the liquid below its glass transition temperature $T_{B}$, can be achieved by this technique. If the liquid is not cooled rapidly enough, a crystalline solid will be produced through a heterogeneous nucleation and growth process.

Figure 1.1 ref. [1] shows the glass and crystal formation paths in a cooling process, as a function of the sample's volume. The liquid to crystal transition is accompanied 


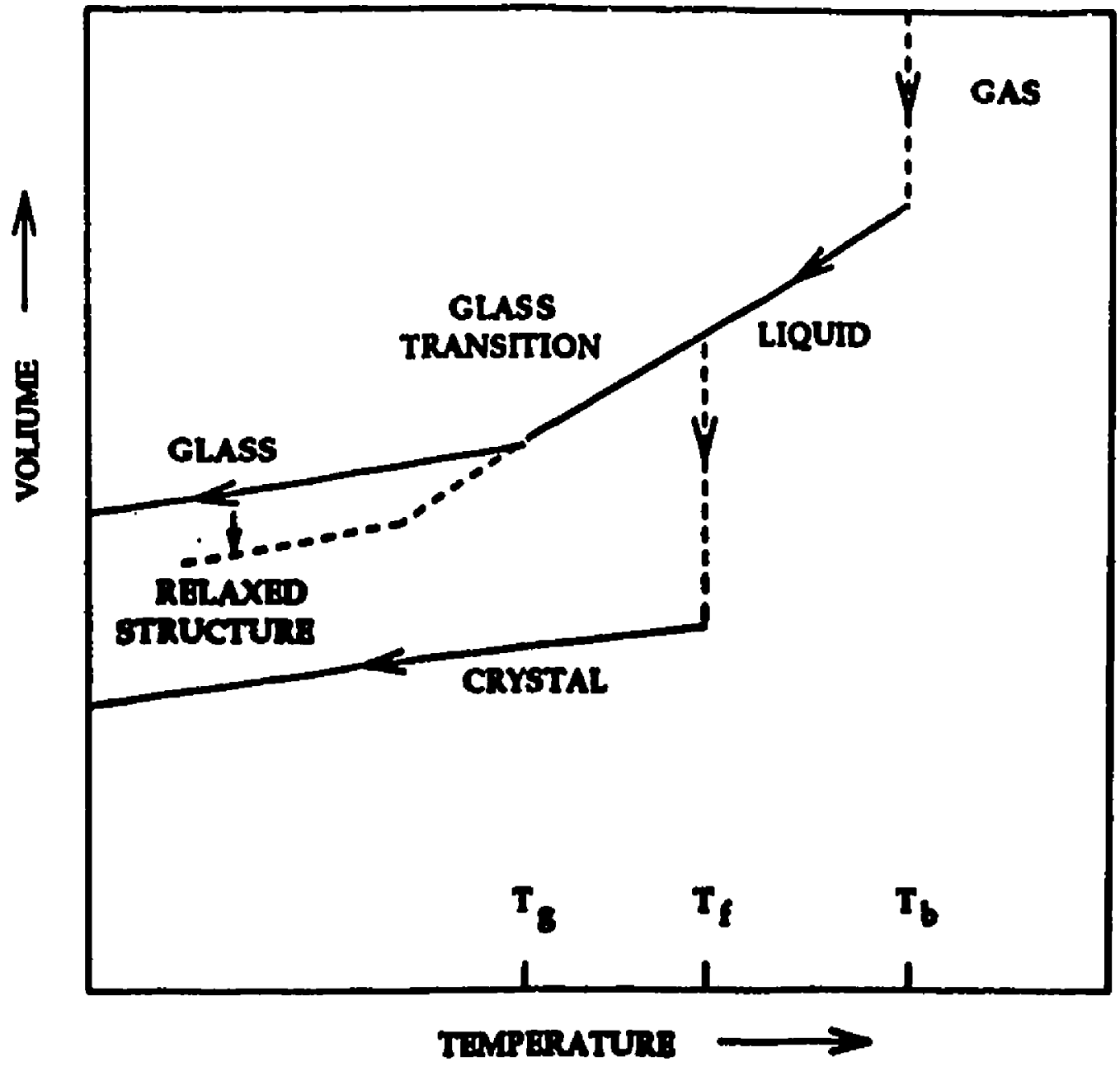

Figure 1.1: Schematic illustration of the change in volume with temperature as a supercooled liquid is cooled through the glass transition temperature $T_{g}$. The first-order phase transition, at $T_{f}$ corresponding to the crystallization from the melt is also shown. The small vertical arrow illustrates the volume change accompanying the structural relaxation. $T_{b}$ is the boiling temperature. (reptoduced from ref. [1])

by a first-order phase transition at melting or crystallization temperature $T_{f}$, while in liquid to glass transition the liquid bypasses $T_{f}$ smoothly and transforms into a glass around $T_{B}$, the glass transition temperature.

In general, a metallic glass can be regarded as a frozen-in liquid in which atoms are not given sufficient time to relax from the high temperature atomic configuration to the low temperature configuration. As is usual, this frozen-in melt structure is not in an internal equilibrium state. Therefore it can relax structurally from this metastable state to a more stable one upon thermal annealing, Figure 1.1. From an energy point of view, the relaxation process allows the atoms to move around on the 
system's potential energy surface until they reach a local minimum [2].

Structural relaxations are categorized in two groups: Irreversible and reversible. Irreversible relaxation is referred as to the changes which occur when the glass is heated for the first time after the melt-quenching process. In this case the state of the glass after relaxation can not be retrieved unless the fabrication process is repeated. On the other hand reversible structural relaxation refers to the structural changes happening in the glass when the temperature is cycled bellow the glass transition temperature between two annealing temperatures after the irreversible relaxation process is achieved. In a reversible structural relaxation all the observables of the material (sample) can be recovered by repeating the same annealing process.

Upon structural relaxation, many physical properties change; some drastically and others slightly. For example diffusivity [3], viscosity [4], mechanical ductility [5], and magnetic anisotropy [6], change drastically, while changes in density are comparatively small [7]. Among those properties affected by structural relaxation, superconducting transition temperature $\left(T_{c}\right)$ is the focus of this work. Variation of $T_{c}$ upon annealing was first observed in amorphous $\mathrm{Z}_{3} \mathrm{Rh}$ by Drehman and Johnson [8]. They showed that in $\mathrm{Zr}_{3} \mathrm{Rh}, \mathrm{T}_{\mathrm{c}}$ decreases according to $\log (\mathrm{t})$ for a length of time $\mathrm{t}$ at an annealing temperature well bellow the glass transition temperature. Since then, many studies on superconducting metallic glasses have been carried out to understand the effects of both irreversible and reversible relaxations on $\mathrm{T}_{\mathrm{c}}$ of metallic glasses. So far, the $\mathrm{T}_{c}$ of amorphous superconductors has been found to decrease upon relaxation [9]. These include $\mathrm{Pd}_{\mathrm{x}} \mathrm{Zr}_{\mathrm{r}_{100-x}}(20<x<40)[10] ; \mathrm{Ni}_{\mathrm{x}} \mathrm{Zr}_{\mathrm{r}_{100-x}}(20<x<35)$; $\mathrm{Zr}_{3} \mathrm{Rh}[8,10]$; $\mathrm{La}_{70} \mathrm{Zr}_{30}$ [11]; $\mathrm{V}_{3} \mathrm{Si} ; \mathrm{Nb}_{3} \mathrm{Ge}$ [12]; $\mathrm{Cu}_{100-x} \mathrm{Zr}_{\mathbf{x}}(30<x<80)$ [13]; Mo - Rh - P [8]. The decrease in $\mathrm{T}_{c}$ upon annealing has been related to the decrease in the electronphonon coupling constant, $\lambda_{e p}$, created by hardening of phonon modes as a result of relaxation of the quenched-in strains or collapse and redistribution of the defects (voids) created by rapid quenching.

Recently a preliminary study [14] showed an unusual increase in $T_{c}$ upon relaxation for Zr-rich Fe-Zr glasses. This motivated us to do a systematic study of 
$\mathrm{Fe}_{\mathrm{x}} \mathrm{Zr}_{\mathrm{r}_{100-\mathrm{x}}}$ metallic glasses. Our choices for the range of the compositions, $20 \leq x \leq$ 33, were limited by the fact that $\mathrm{Fe}_{\mathrm{x}} \mathrm{Z}_{\mathrm{r}_{100-x}}$ glasses with $x<20$ are very difficult to manufacture by melt-quenching techniques. On the other hand an extrapolation of previous studies [15] on the superconductivity of as-quenched $\mathrm{Fe}-\mathrm{Zr}$ metallic glasses indicated that $T_{c}$ for $x \leq 33$ would be below $10 \mathrm{mK}$, beyond the limit of our cryogenic equipment $(20 \mathrm{mK})$. The present work is aimed at three targets: (i) to confirm the observed increase in $\mathrm{T}_{c}$ in $\mathrm{Zr}$-rich $\mathrm{Fe}-\mathrm{Zr}$ metallic glasses upon relaxation, (ii) to provide a theoretical basis for this $T_{c}$ enhancement, and (iii) to give a qualitative or quantitative experimental evidence in support of this theory to explain this unusual phenomenon.

This thesis is organized as follows. In Chapter 2, preparation and characterization of the samples together with the experimental methods used for the measurements are explained in detail. Chapter 3 starts with a brief review of the theories of superconductivity in metallic glasses and recent modifications in these theories, and continues with the results of the experimental measurements. Later in this Chapter, these experimental results are analyzed by using the modified McMillan equation which includes the effects of spin fluctuations. Finally, Chapter 4 gives a final look at the important results of this work. 


\section{Chapter 2}

\section{Experimental Methods}

\subsection{Sample Preparation}

Fourteen glassy ribbons of compositions $\mathrm{Fe}_{\mathrm{x}} \mathrm{Z}_{\mathrm{r}_{100-\mathrm{x}}}$ with $20 \leq x \leq 33$ were prepared by the melt-spinning technique. The pure elements were obtained from Alpha Product Company with $\mathrm{Zr}$ of purity $99.95 \%$ and $\mathrm{Fe}$ of purity $99.99 \%$. Since the Zirconium was originally in a crystal bar shape, it had to be cut into small pieces. To remove any possible surface contaminants from the cutting tools, pieces of $\mathrm{Zr}$ were etched by using $\mathrm{H}_{2} \mathrm{O} / \mathrm{HF} / \mathrm{H}_{2} \mathrm{O}_{2}(20: 1: 1)$, followed by immersion in ethanol to stop any further reaction.

For each composition, appropriate amounts of iron and zirconium were weighed and melted together in an arc furnace under a zirconium gettered prepurified argon atmosphere. The resultant ingots were turned over and remelted at least three times to ensure their compositional homogeneity. At the end of the melting process all the ingots were weighed to estimate the mass loss. Compared to the original masses of the raw materials, the weight loss was typically less than $1 \%$.

Amorphous ribbons of each composition were made by the melt-spinning technique. A schematic diagram of melt-spinning equipment is shown in Figure 2.1. Ingots of about $1.3 \mathrm{~g}$ mass were melted inside quartz crucibles under $15 \mathrm{kPa}$ helium pressure and were propelled out of the crucible through an orifice of $\sim 0.4 \mathrm{~mm}$ in 
diameter, under the pressure of $\sim 100 \mathrm{kPa}$ argon gas, against the surface of a rotating copper disk. Tangential velocity of the copper disk was approximately $50 \mathrm{~m} / \mathrm{s}$. In this way amorphous ribbons of about 1 meter long and $15 \mu \mathrm{m}$ thick and 2 millimeter in width were produced.

\subsection{Characterization}

Both X-ray diffraction and differential scanning calorimetry (DSC) were used to probe the crystallization characteristics of the as-quenched ribbons.

\subsubsection{X-ray Diffraction}

The structural states of the as-made ribbons were examined by $\mathrm{X}$-ray diffraction in reflection mode using monochromated $\mathrm{CuK}_{\alpha}$ radiation $(\lambda=1.5418 \AA)$. The diffractometer was an automated Nicolet-Stöe powder diffractometer. A schematic diagram of the X-ray diffractometer is shown in Figure 2.2. To make sure that any possible crystallization would be detected, the free side of the ribbons which during meltspinning were not in contact with the copper disk, and consequently experienced a lower cooling rate, were faced against the incident radiation. A scanning range of $20 \leq 2 \theta \leq 80$ was covered with 0.1 degree per scanning step and a $10 \mathrm{~s}$ scanning time per step.

The diffraction pattern for all 14 samples showed broad peaks typical for amorphous materials. As an example Figure 2.3 shows the $\mathrm{X}$-ray diffraction pattern for the composition $\mathrm{Fe}_{33} \mathrm{Zr}_{67}$. The first peak indicates the short range order corresponding to the coordination shells of the nearest neighbours. 


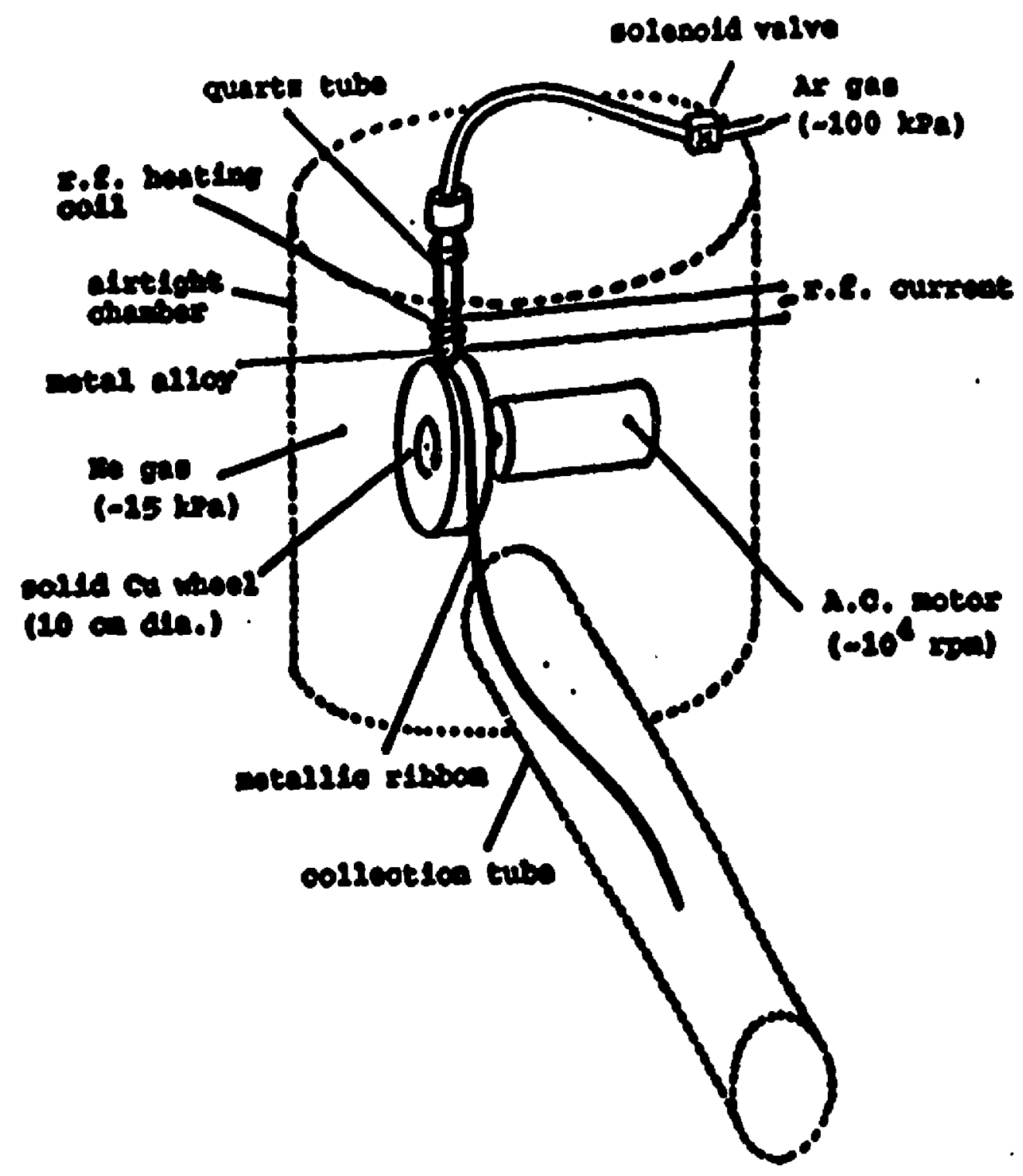

Figure 2.1: Schematic diagram of the melt-spinning apparatus. 


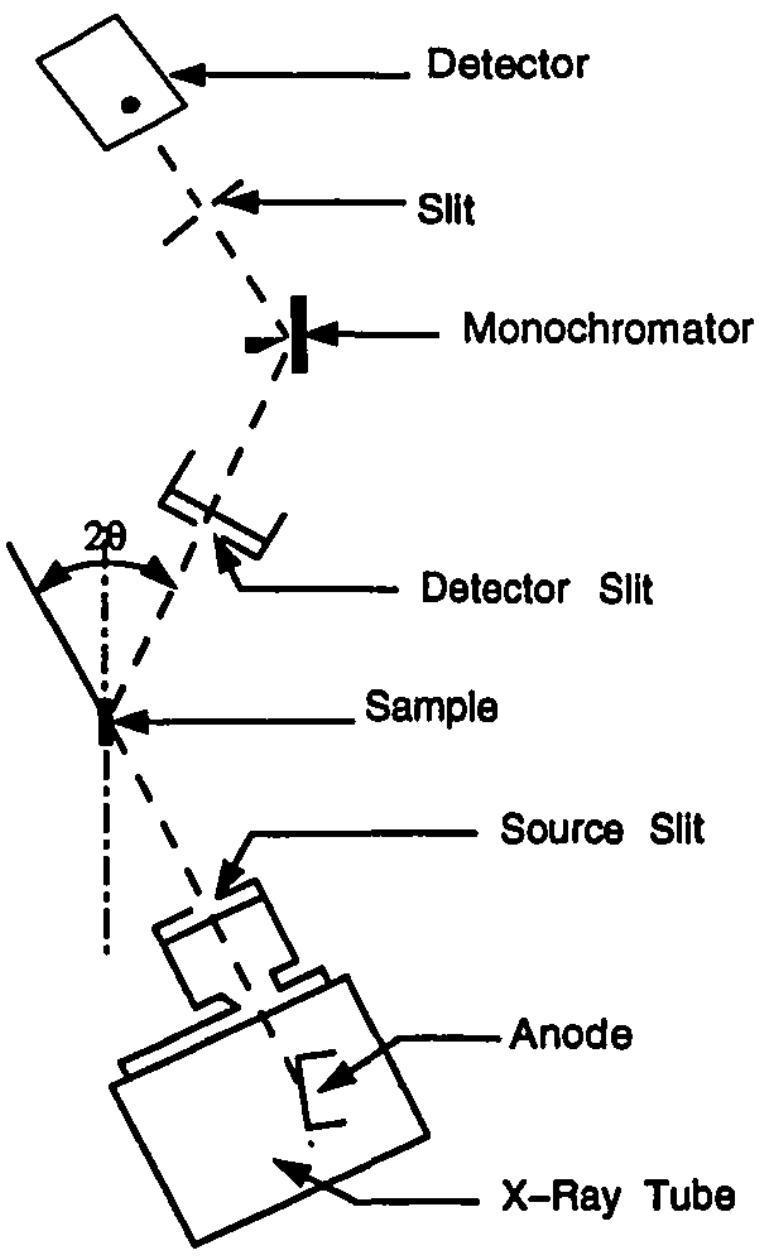

Figure 2.2: A schematic drawing of the X-ray diffractometer. 


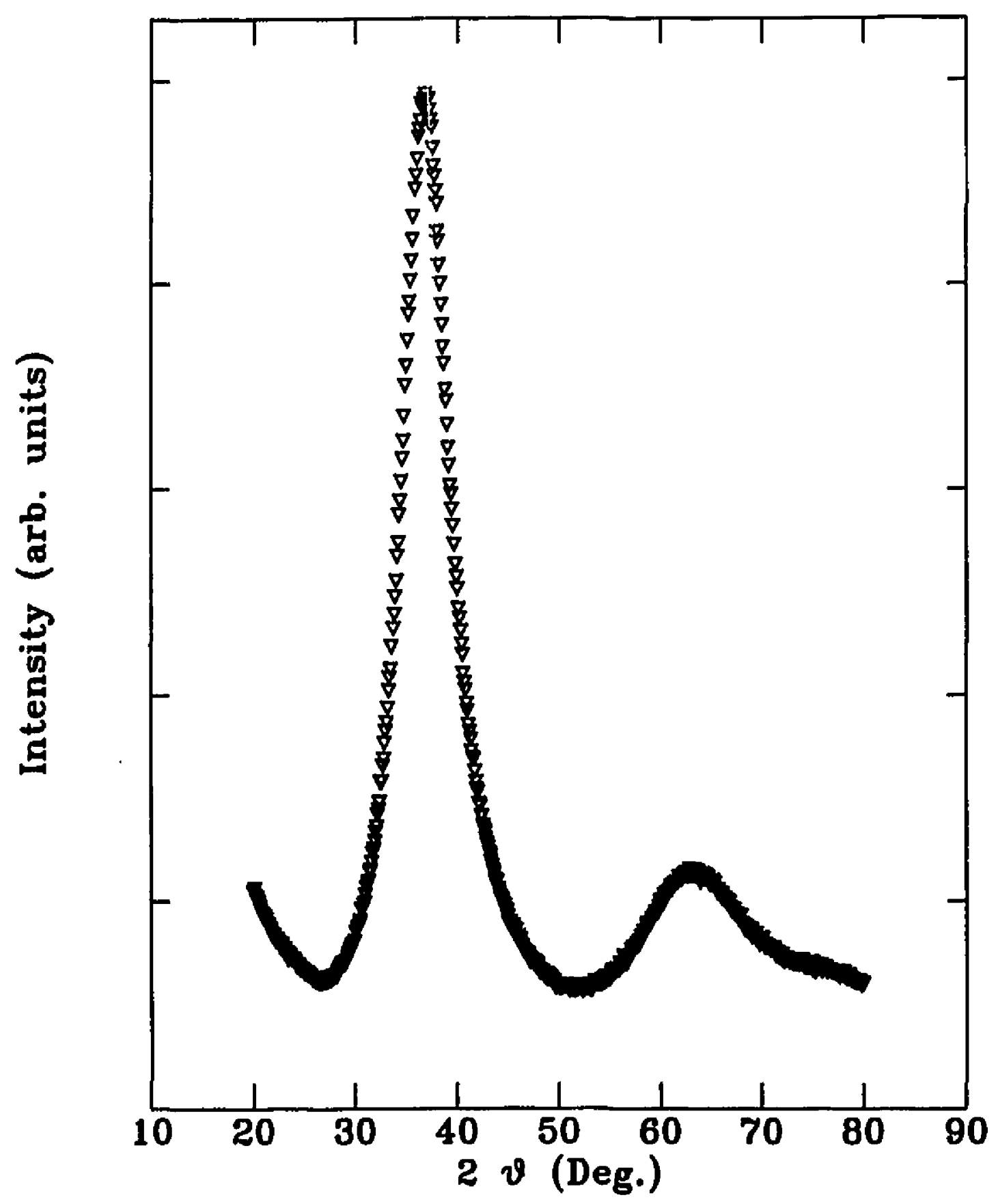

Figure 2.3: X-ray diffraction pattern, showing the amorphous nature of Fes8 $Z_{\text {re7. }}$. 


\subsubsection{Differential Scanning Calorimetry (DSC)}

Amorphous alloys are metastable and crystallize when they are heated to a certain temperature $T_{x}$, the crystallization temperature, below their melting point [16]. The crystallization is accompanied by a change in the enthalpy of the alloy from the amorphous state to the crystalline state. Both crystallization temperature and crystallization enthalpy can be used to characterize the amorphous alloys and are important parameters that can be used to confirm the compositional homogeneity of the alloys.

All ribbons were subjected to differential scanning calorimetry (DSC) using a Perkin-Eilmer DSC 2C. The scans were done in isochronal mode with a heating rate of $40 \mathrm{~K} / \mathrm{min}$. Ribbons of about 7 to $9 \mathrm{mg}$ were placed in an aluminum pan, which in turn was placed in a platinum sample holder. An empty pan placed in an identical sample holder is used as a reference. During measurements samples were exposed to a constant flow of Argon gas, 24 psi pressure to protect the samples from oxidation.

\subsubsection{Electron Beam Microprobe Measurements}

The composition of the samples were determined by electron beam microprobe analysis using a JEOL 8900 electron microprobe. In this analysis, glassy ribbons of 2.5 cm long, are irradiated with an electron beam which excites the electrons in the inner atomic shells. The excited electrons decay and emit a characteristic X-ray. The intensity of the emitted X-ray is proportional to the concentration of the elements in the sample. Table 2.1 shows the results of these measurements. It is clear from table 2.1, that the measured compositions are in agreement with the nominal values within the instrumental resolution $(\sim \pm 0.5$ at. $\%)$. 
Table 2.1: Electron microprobe results. The first column shows the compositions with their nominal atomic percentage of constituents. The second and third columns show the measured values of the atomic percentages of the elements $\mathrm{Fe}$ and $\mathrm{Zr}$ within ( \pm 0.5 at. \%).

\begin{tabular}{|c|c|c|}
\hline Composition & $\mathrm{Fe}$ (at. \%) & $\mathrm{Zr}$ (at. \%) \\
\hline $\mathrm{Fe}_{20} \mathrm{Z}_{\mathrm{r}_{80}}$ & 20.5 & 79.5 \\
\hline $\mathrm{Fe}_{21} \mathrm{Z}_{\mathrm{r}_{79}}$ & 21.3 & 78.6 \\
\hline $\mathrm{Fe}_{22} \mathrm{Z}_{\mathrm{r}_{78}}$ & 22.4 & 77.5 \\
\hline $\mathrm{Fe}_{23} \mathrm{Z}_{\mathrm{r}_{77}}$ & 23.3 & 76.7 \\
\hline $\mathrm{Fe}_{24} \mathrm{Zr}_{76}$ & 24.0 & 75.9 \\
\hline $\mathrm{Fe}_{25} \mathrm{Z}_{75}$ & 25.1 & 74.9 \\
\hline $\mathrm{Fe}_{26} \mathrm{Z}_{\mathrm{r}_{74}}$ & 26.4 & 73.6 \\
\hline $\mathrm{Fe}_{27} \mathrm{Z}_{\mathrm{r}_{73}}$ & 27.1 & 72.8 \\
\hline $\mathrm{Fe}_{28} \mathrm{Z}_{\mathrm{r}_{72}}$ & 28.3 & 71.7 \\
\hline $\mathrm{Fe}_{{ }_{28}} \mathrm{Z}_{\mathrm{r}_{71}}$ & 28.8 & 71.1 \\
\hline $\mathrm{Fe}_{30} \mathrm{Z}_{\mathrm{r}_{70}}$ & 29.3 & 70.7 \\
\hline $\mathrm{Fe}_{31} \mathrm{Z}_{69}$ & 31.0 & 69.0 \\
\hline $\mathrm{Fe}_{32} \mathrm{Z}_{\mathrm{r}_{68}}$ & 31.7 & 68.3 \\
\hline $\mathrm{Fe}_{{ }_{33}} \mathrm{Z}_{\mathrm{r}_{67}}$ & 32.2 & 67.8 \\
\hline
\end{tabular}

\subsection{Density Measurements}

The mass density of some of the samples was measured using the Archimedes' principle. Previous measurements $[15,17]$ have shown that the variation of the density with composition is linear in this range, so we decided to do the measurements for four samples and by interpolation, obtain the densities for the rest of the samples.

In order to reduce the effect of surface tension on the results of the measurements, two measuring platforms were connected with a thin quartz fiber. Using a Mettler H20T mechanical balance, the weight of the samples in air and in tetrabromoethane, 
Table 2.2: Density measurements results

\begin{tabular}{|c|c|c|}
\hline Composition & Density $\left(\mathrm{g} / \mathrm{cm}^{3}\right)$ & Error \\
\hline $\mathrm{Fe}_{20} \mathrm{Z}_{\mathrm{I}_{80}}$ & $6.70^{a}$ & \pm 0.04 \\
\hline $\mathrm{Fe}_{21} \mathrm{Zr}_{79}$ & $6.70^{6}$ & \\
\hline $\mathrm{Fe}_{22} \mathrm{Z}_{\mathrm{I}_{78}}$ & $6.71^{b}$ & \\
\hline $\mathrm{Fe}_{23} \mathrm{Zr}_{77}$ & $6.73^{b}$ & \\
\hline $\mathrm{Fe}_{24} \mathrm{Zr}_{76}$ & $6.73^{a}$ & \pm 0.03 \\
\hline $\mathrm{Fe}_{25} \mathrm{Z}_{575}$ & $6.75^{b}$ & \\
\hline $\mathrm{Fe}_{26} \mathrm{ZI}_{74}$ & $6.77^{b}$ & \\
\hline $\mathrm{Fe}_{27} \mathrm{Z}_{73}$ & $6.78^{b}$ & \\
\hline $\mathrm{Fe}_{28} \mathrm{Zr}_{72}$ & $6.79^{b}$ & \\
\hline $\mathrm{Fe}_{29} \mathrm{Zr}_{71}$ & $6.80^{a}$ & \pm 0.03 \\
\hline $\mathrm{Fe}_{30} \mathrm{Z}_{I_{70}}$ & $6.82^{6}$ & \\
\hline $\mathrm{Fe}_{31} \mathrm{ZI}_{69}$ & $6.84^{b}$ & \\
\hline $\mathrm{Fe}_{32} \mathrm{Zr}_{68}$ & $6.85^{b}$ & \\
\hline $\mathrm{Fe}_{33} \mathrm{Z}_{\mathrm{I}_{67}}$ & $6.86^{b}$ & \pm 0.06 \\
\hline
\end{tabular}

${ }^{a}$ Measured data

${ }^{b}$ Interpolated data

$\left(\mathrm{C}_{2} \mathrm{H}_{2} \mathrm{Br}_{4}\right.$, with density $\left.\rho_{2} \mathrm{H}_{2} \mathrm{Br}_{4}=2.9 \mathrm{~g} / \mathrm{cm}^{3}\right)$ was measured. The density of the sample, $\rho_{s}$ can be obtained from the following formula:

$$
\rho_{\mathrm{s}}=\frac{W_{\mathrm{air}}}{W_{\mathrm{air}}-W_{C_{2} \mathrm{H}_{2} \mathrm{Brd}_{\mathrm{d}}}} \rho_{C_{2} \mathrm{H}_{2} \mathrm{Br}_{\mathrm{s}}}
$$

where $\mathrm{W}_{\mathrm{air}}$ is the sample's weight in the air, and $\mathrm{W}_{\mathrm{C}_{2} \mathrm{H}_{2} \mathrm{Br}_{4}}$ is the sample's weight in tetrabromoethane. Table 2.2 shows the measured and interpolated densities obtained for all the samples. 


\subsection{Room Temperature Resistivity Measurements}

A four probe DC measurement technique was used to determine the room temperature resistance of the ribbons. the current and voltage contacts to the samples were made using a set of very sharp arms made from brass. A $50 \mathrm{~mA}$ current was applied by a Keithley 225 current source to the samples and the resultant voltage across each sample was measured by a Keithley 199 multimeter. In these type of measurements there is always a possibility that both contact potential and Seebeck e.m.f [18] can develop at the junction between the sample and the contact arm. Since both contact potential and Seebeck e.m.f are independent of the polarity of the current, they will not be affected by current reversal. Therefore to remove these contributions from our measurements the voltage across each sample was measured with a reversed current and subtracted from the previously measured voltage across the sample with unreversed current. By dividing the result which would be twice the value of the actual voltage due to the current, by two an accurate value of the voltage across each sample was obtained. To convert the resistance to resistivity, normally we need to know the cross section of the sample. Since a direct measurement of the ribbons' cross section is very difficult, we use the measured density of the ribbons and manipulating the equation for resistivity $\rho=\mathrm{RA} / \mathrm{L}$ we can obtain the room temperature resistivity from the following formula:

$$
\rho=\frac{R m}{d L^{2}}
$$

where $R$ is the room temperature resistance, $L$ is the ribbon length, $m$ is the mass, and $d$ is the dersity of the ribbon.

\subsection{Annealing Technique}

Irreversible structural relaxation of the samples was performed by short range annealing, using the DSC in isochronal mode. For each sample, two pieces of 4-5 mm long ribbons were heated up to $40 \mathrm{~K}$ below the onset of their crystallization temperature 
with a $40 \mathrm{~K} / \mathrm{min}$ heating rate and immediately cooled down to room temperature immediately with a $320 \mathrm{~K} / \mathrm{min}$ cooling rate. A constant oxygen- free argon gas flow with 24 psi pressure was maintained over the samples during the annealing opperation. To prevent any furthur risk of oxidation the annealed ribbons were kept under the oxygen- free Argon gas flow for at least half hour before removing them from the DSC chamber.

\subsection{SQUID Measurements}

Susceptibility, $\chi$, and superconducting transition temperature, $T_{c}$, of the as-made and relaxed samples were measured using a model MPMS Quantum design SQUID magnetometer in Prof. S.F. Razavi's laboratory at Brock University, St.Catharine, Ontario. Because of a problem in mounting the samples inside the SQUID we could not measure the absolute value of the magnetization. This meant that absolute susceptibility values could not be determined. This problem had less effect on superconducting transition temperature, $T_{c}$, measurements. This is because $T_{c}$ was obtained from the sudden change in magnetization as a function of temperature. Susceptibility measurements were repeated later in Prof. C.V. Stager's laboratory at McMaster University, Hamilton, Ontario, by measuring the magnetization (M) of the samples as a function of magnetic field (H). For each sample, 6 pieces of $5 \mathrm{~mm}$ long ribbons were mounted side by side and parallel to the direction of the applied magnetic field inside a milkshake straw using a small amount of Ge varnish. It is always possible that during the manufacturing of the ribbons, small clusters of iron or iron-rich compounds can develop on the surface of the ribbons. These small clusters, if ferromagnetic, can introduce non-linear effects in the field dependance of the magnetization. In such cases, the effects of these ferromagnetic impurities can be removed from the susceptibility by using a technique called the Honda plot. In this technique the paramagnetic susceptibility of the sample is obtained from the extrapolation of the measured susceptibility values at high magnetic fields in a plot of $\chi$ vs. $1 /$ H to 
infinite field, which corresponds to $1 / \mathrm{H}=0$. This technique is based on the fact that at high magnetic fields $(1 / \mathrm{H} \rightarrow 0)$, because of the saturation of the magnetization, the ferromagnetic susceptibility tends to zero and therefore the measured susceptibility of the sample at high magnetic fields shows only the paramagnetic susceptibility of the sample. Since our samples are paramagnetic, during the susceptibility measurements all the as-quenched and relaxed samples were exposed to magnetic fields of up to 4 Tesla to have enough data to remove the effects of possible ferromagnetic impurities.

The superconducting transition temperature was measured at five different fields: $10 \mathrm{G}$ (essentially zero field), $2510 \mathrm{G}, 5010 \mathrm{G}, 7510 \mathrm{G}$, and $10010 \mathrm{G}$ by decreasing the temperature from $4 \mathrm{~K}$ down to the lowest temperature available by the SQUID $(1.8 \mathrm{~K})$. Since the SQUID was not able to cover temperatures lower than $1.8 \mathrm{~K}, \mathrm{~T}_{\mathrm{c}}$ measurements for samples with a $T_{c}$ lower than $1.9 \mathrm{~K}$ was not possible with the SQUID magnetometer.

\subsection{Dilution Fridge Measurements}

As mentioned in the previous section, superconducting measurements for temperatures bellow $1.9 \mathrm{~K}$ with the SQUID were not possible. Therefore we had to continue our measurements with a dilution fridge to cover very low temperatures. Using an Oxford Instrument dilution fridge model Kelvinox 300 in Prof. L. Taillefer's laboratory, McGill University, and a four probe $\mathrm{AC}$ measurement technique $T_{c}$ of the samples were measured from the change in the samples' resistance with temperature. A schematic diagram of the experimental set up is shown in Figure 2.4. Ribbons of typically $5 \mathrm{~mm}$ long were mounted on a sample mount using GE varnish. Sample mounts are made from a square copper sheet of sides of $1 \mathrm{~cm}$ long sides and $1 \mathrm{~mm}$ thick and electrically insulated one side with paper tissue and a thin layer of epoxy glue. The sample mounts were attached to the sample holder at the bottom of the dilution fridge by using a thin layer of vacuum grease. copper wires of $0.04 \mathrm{~mm}$ diameter were used as current and voltage leads. The connection between the wires 
and the samples were made by using a TRA-DUCT 2902 silver epoxy.

Although by heating the contacts at $110^{\circ} \mathrm{C}$ we could achieve contacts with lower resistivity (volume resistivity of $0.003 \mathrm{Ohm} \cdot \mathrm{cm}$ ), the contacts were cured at room temperature (with volume resistivity of $0.03 \mathrm{Ohm}-\mathrm{cm}$ ) to avoid introducing any possible relaxation effects on the as-made samples during the curing process. Obviously heating the contacts at $110^{\circ} \mathrm{C}$ centigrade for the relaxed samples would not cause any problems as the relaxed samples were annealed at temperatures much higher than 110 ${ }^{\circ} \mathrm{C}$. But, to preserve the similarity of the conditions for as-made and relaxed samples, we decided to follow the room temperature cure for the contacts in the relaxed samples as well. The temperature of the sample was monitored by a Ruthenium Oxide $\left(\mathrm{RuO}_{2}\right)$ thermometer which was calibrated by a Germanium thermometer. the temperature was controlled by a Rv-Electronica model TS-530 temperature controller which was connected to a LR-400 AC resistance bridge where the temperature was monitored as the corresponding resistance. A voltage of $3 \mathrm{~V}$ was applied to the sample by a model SR-850 lock-in amplifier (Standard Research, USA). Since the SR-850 lock-in is a voltage source, a $1 \mathrm{M} \Omega$ standard resistor was connected between the sample and lock-in to get the desired low current $(3 \mu \mathrm{A})$. The output voltage across the sample which is directly proportional to the sample's resistance through $\mathrm{Ohm}$ law, was measured by the same SR-850 lock-in and was stored in a Macintosh IIci personal computer. Magnetic field dependence of the resistivity was measured by applying a magnetic field in the plane of the sample, parallel to the direction of the current in the sample. Changing the temperature and magnetic field and data acquisition were automatically performed by a computer program package (Labview-2), and a Macintosh IIci PC. The results were transformed to a Sun microcomputer station for further analysis.

Starting with the lowest temperature $(20 \mathrm{mK})$ available from the dilution fridge, three samples including $\mathrm{Fe}_{33} \mathrm{Z}_{\mathrm{r}_{67}}, \mathrm{Fe}_{32} \mathrm{Z}_{\mathrm{r}_{68}}, \mathrm{Fe}_{31} \mathrm{Z}_{\mathrm{r}_{69}}$ did not show any transition to the superconducting phase. This gave us a lower limit for the superconductivity of our Fe$\mathrm{Zr}$ compositions. In the next step zero field superconducting transition temperature 


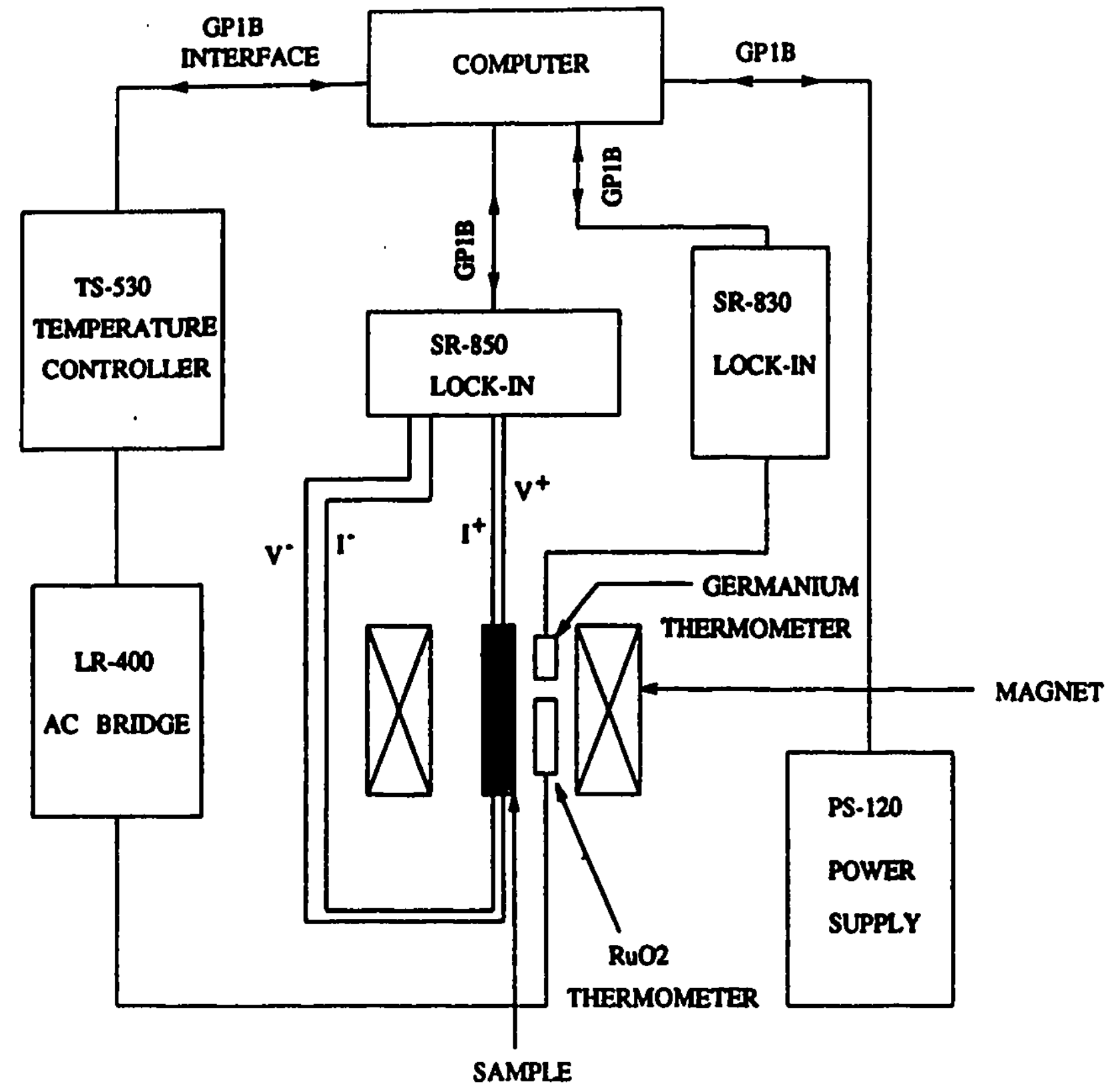

Figure 2.4: A schematic diagrem of the dilution fridge set up 
and field dependance of $T_{c}$ were measured for a pair of as-made and relaxed $\mathrm{Fe}_{30} \mathrm{Zr}_{\mathrm{r}_{70}}$ samples. It is important to mention that, due to technical reasons our method for measuring the field dependance of $T_{c}$ with the dilution fridge was different from the method we used for the same measurement with the SQUID magnetometer. In the dilution fridge, the temperature $\left(T_{c}\right)$ was fixed first and then by sweeping the magnetic field, the corresponding $\mathrm{H}_{\mathrm{c} 2}$ was found, while in measurement with the SQUID as mentioned before, the magnetic field $\mathrm{H}_{\mathrm{c} 2}$ was fixed and by sweeping the temperature, $T_{c}$ was obtained. Theoretically there should be no difference between these two methods. But, this was not the case for our measurement of $T_{c}$ in the dilution fridge and affected our results in an adverse way due to flux trapping inside the sample and consequently self heating of the sample, discussed later in this section.

After collecting a series of clean superconducting transitions up to $190 \mathrm{mK}$, the data for the as-made sample at $200 \mathrm{mK}$ and for the relaxed sample at $210 \mathrm{mK}$ showed an increasing nonzero resistivity after the superconducting transition to zero resistivity. The results of the $T_{c}$ measurements for relaxed sample at three different temperatures are shown in Figures 2.5-2.7. At higher temperatures this effect became so dominant that one cannot determine $T_{c}$. As we discovered upon further analysis that for each new temperature, the magnetic field changes in a few seconds from zero to a new field value before being swept down. There is a possibility, therefore, that a magnetic flux could be trapped inside the sample producing an eddy current. The magnitude of this induced eddy current is high compared to the small current $(3 \mu \mathrm{A})$ applied originally to the sample by the lock-in. On the other hand, since the contact resistance is $\sim 10 \Omega$, approximately $10^{3}$ times larger than the sample's resistances (250 $\mathrm{m} \Omega$ ), the eddy current through the contacts will generate a Joule heating process. The amount of the generated heat is equal to $R_{C} I_{E}^{2}$, where $R_{c}$ is the contact resistance and $I_{E}$ is the eddy current. The amount of heat increases with field and increases the sample's temperature and hence its resistivity. The increase in resistivity becomes more dominant if the heat is not transformed from the sample to the surrounding Helium environment efficiently. This tells us that although paper tissue is good for 
electrical insulation, it is not a good choice for heat conduction. A thin layer of mylar could have been a better choice for this purpose. Unfortunately, due to maintenance operations and other technical problems of the dilution fridge, we were not able to continue our measurements with the dilution fridge. 


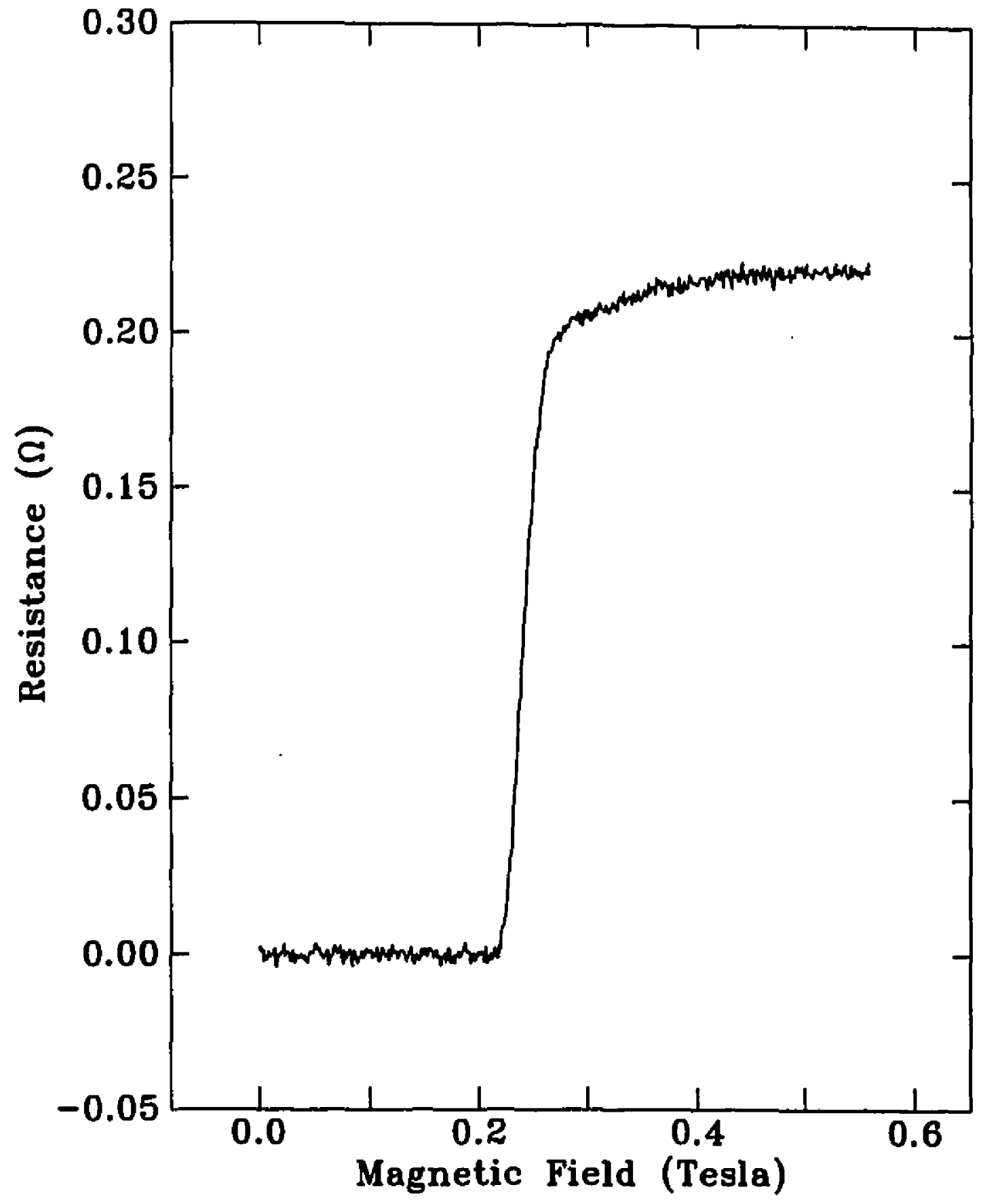

Figure 2.5: Resistance versus applied magnetic field for relaxed $\mathrm{Fe}_{30} \mathrm{Zr}_{70}$ at $\mathrm{T}=0.140 \mathrm{~K}$ 


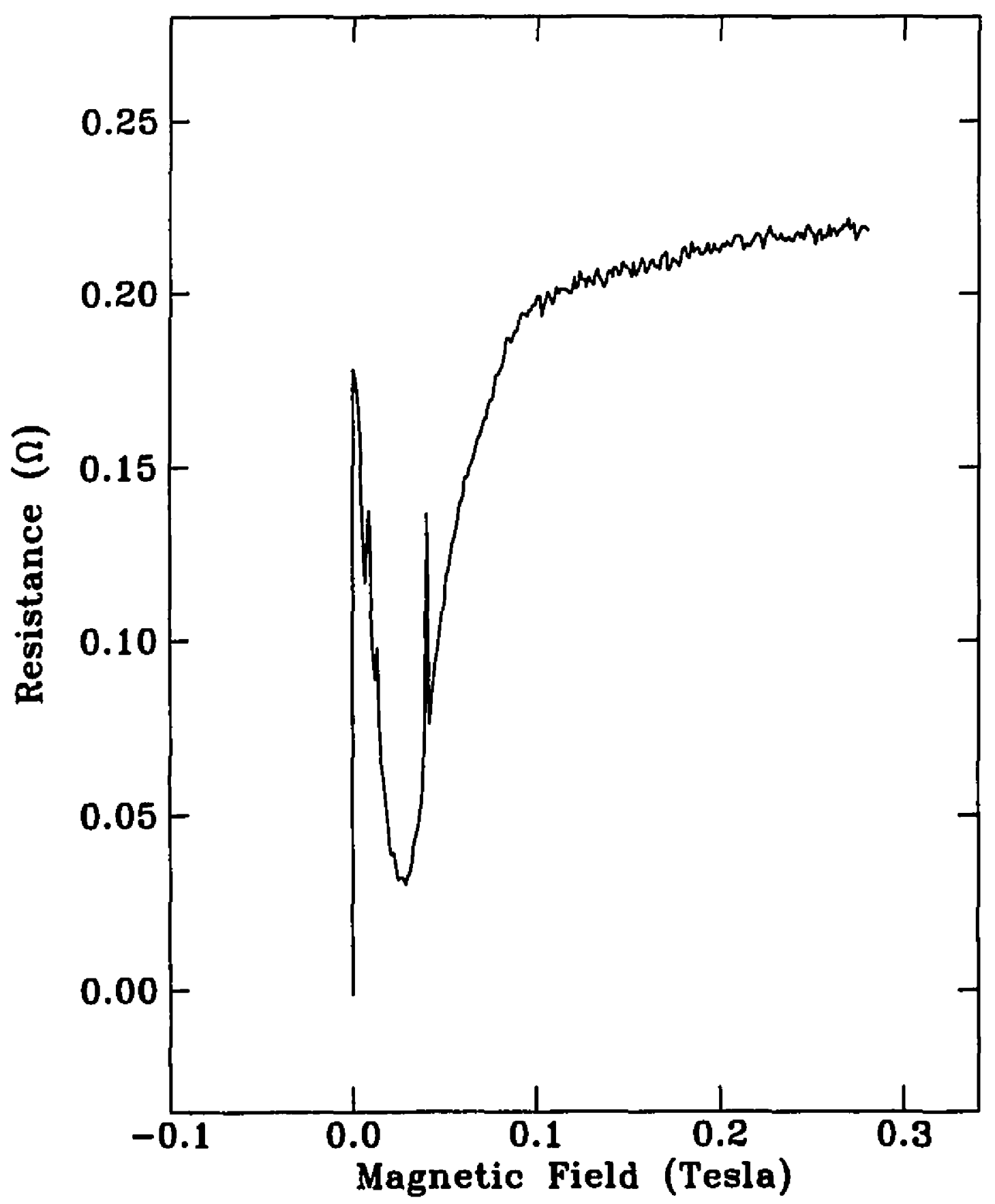

Figure 2.6: Resistance versus applied magnetic field for relaxed $\mathrm{Fe}_{80} \mathrm{Zr}_{\mathrm{ro}}$ at $\mathrm{T}=0.210 \mathrm{~K}$ 


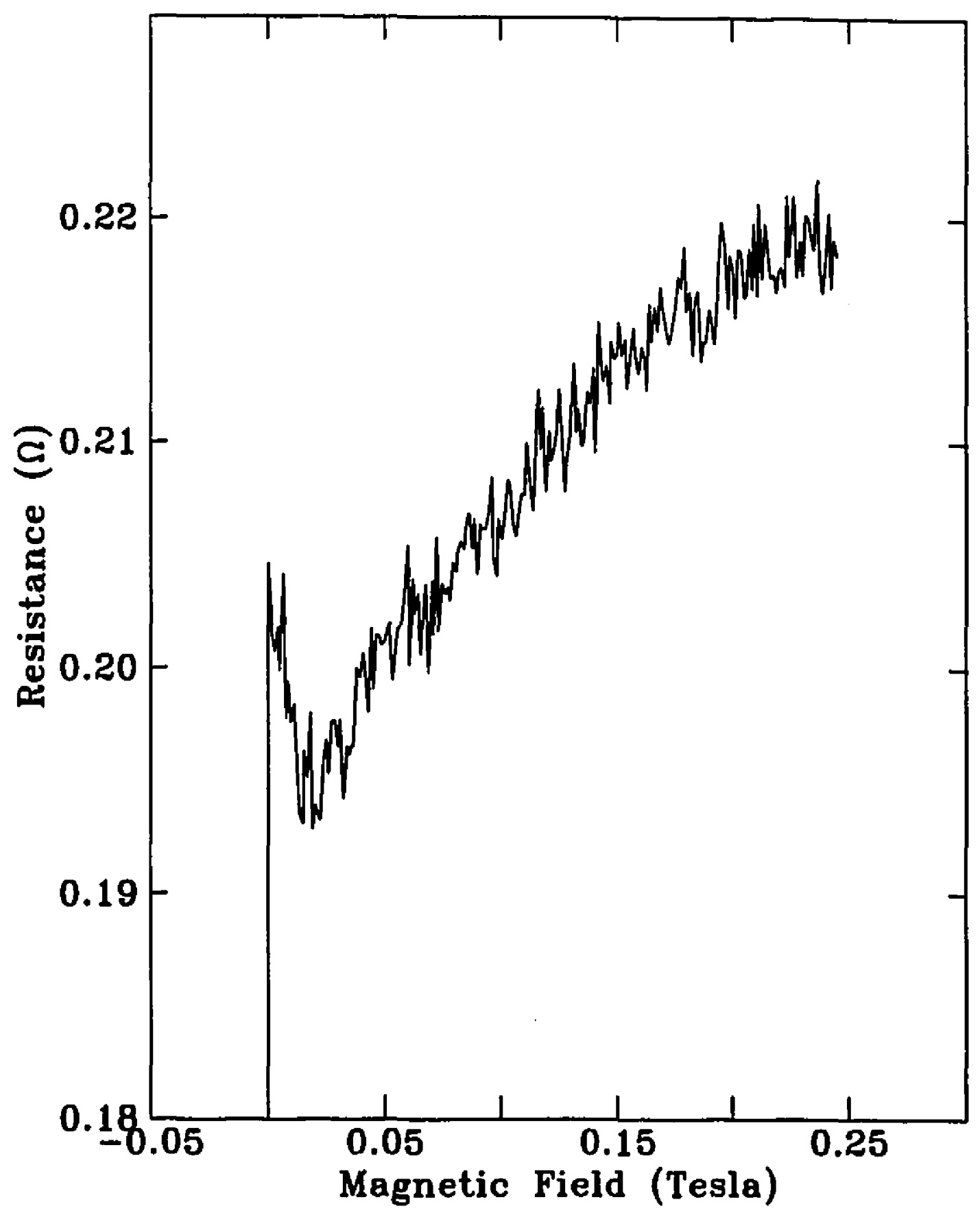

Figure 2.7: Resistance versus applied magnetic field for relaxed FesoZzro at $T=0.230 \mathrm{~K}$ 


\section{Chapter 3}

\section{Results and Discussions}

\subsection{Superconductivity In Amorphous Metallic Al- loys: Theoretical Background}

Superconductivity in amorphous materials was discovered for the first time by Hilsh and Buckel [19] in vapour-quenched thin films of Bismuth and Gallium. It was not until 1975 that superconductivity was observed in a series of melt-quenched amorphous materials [20].

A superconductor held parallel to a weak applied magnetic field $\mathrm{H}_{0}$ has the property that the field can penetrate only a short distance $\Lambda$ into the sample. Beyond this distance, which is known as the penetration depth and is typically of the order of $0.1 \mu \mathrm{m}$, the field decays rapidly to zero. This is known as Meissner effect and is sometimes thought of as "perfect diamagnetism". If the strength of the magnetic field is increased the superconductivity is eventually destroyed, and this can happen in two ways. In a type I superconductor the specimen becomes normal at an applied field $H_{\mathrm{c} 1}$ and the magnetic field inside the sample changes from zero to a value close to $\mathrm{H}_{0}$. In a type II superconductor, on the other hand, although the magnetic field starts to penetrate the sample at an applied field $\mathrm{H}_{\mathrm{c1}}$, it is not until a greater field, $H_{c 2}$, is reached, that the field within the sample approaches $H_{0}$. For applied fields 
between $\mathrm{H}_{\mathrm{c} 1}$ and $\mathrm{H}_{\mathrm{c} 2}$ the sample is in a mixed state consisting of a superconductor penetrated by threads of the material in its normal state. The type of a superconductor can be determined more or less quantitatively by the Ginzburg-Landau [21] parameter defined as:

$$
\kappa=\frac{\Lambda(T)}{\zeta(T)}
$$

where $\Lambda(T)$ is the field penetration depth and $\zeta$ is the coherent length defined as:

$$
\zeta=\frac{\hbar v_{f}}{\pi \Delta(T)}
$$

where $v_{f}$ is the Fermi velocity and $\Delta(T)$, an energy of the order of $\mathrm{KT}_{c}$, is the energy gap. Type I superconductors have $\kappa<1 / \sqrt{2}$ while type II superconductors have $\kappa>1 / \sqrt{2}$. For amorphous superconductors $\kappa$ is approximately in the range of $40<\kappa<100,[22]$, therefore they are categorized as type II superconductors.

A more detailed understanding of the superconductivity in amorphous alloys is possible by using the recently developed theories about superconductivity. According to microscopic theories, superconducting materials with crystalline structure are classified in two groups, weak-coupling superconductors and strong-coupling superconductors. In weak-coupling superconductors, according to BCS theory [23], electrons are considered to be free particles which have a weak interaction with each other through a phonon- mediated potential. The superconducting transition temperature for this group is expressed by the following formula:

$$
T_{c}=1.14 \omega_{D} \exp [-1 / N(0) V]
$$

where $\omega_{D}$ is the Debye frequency, $N(0)$ is the electronic density of states at the Fermi level, and $\mathrm{V}$ is the effective weak phonon-mediated electron pairing potential. By defining $\lambda_{\mathrm{ep}}=\mathrm{N}(0) \mathrm{V}$ as the electron-phonon coupling constant the above formula takes the following form:

$$
T_{c}=1.14 \omega_{D} \exp \left[-1 / \lambda_{e p}\right]
$$


For weak coupling superconductors $\lambda_{\text {ep }} \ll 1$.

In strong-coupling superconductors with $\lambda_{\text {ep }} \approx 1$, the interaction of the electrons with the phonons depends on both frequency and momentum of the phonons.Moreover in these superconductors, phonons are considered to be distributed in energy with a frequency dependent density of states. One may understand the influence of a strong electron -phonon interaction, qualitatively by considering an electron which tunnels into the superconductor, where it occupies an excited state [24]. In the presence of an electron-phonon interaction the electron has only a finite life time in this state and makes a transition into a lower state by emitting a phonon. This transition probability is determined by Eliashberg function $\alpha^{2} \mathrm{~F}(\omega)$, where $\mathrm{F}(\omega)$ is the density of phonon states and $\alpha$ is an averaged electron-phonon matrix-element [24]. For example an excited electron above the Fermi surface can emit a phonon of energy $\hbar \omega$ with a probability proportional to $\alpha^{2} F(\omega)$. Using the Eliashberg function one can define the electron-phonon coupling constant $\lambda_{\text {ep }}$ as follow:

$$
\lambda_{e p}=2 \int_{0}^{\infty} \frac{\alpha^{2} F(\omega)}{\omega} d \omega
$$

Further developments in the theory of strong-coupling, by McMillan [25] showed that, $T_{c}$, in simple metals can be obtained by the following particular solution of the Eliashberg equation:

$$
T_{c}=\frac{\Theta_{D}}{1.45} \exp \left[-\frac{1.04\left(1+\lambda_{e p}\right)}{\lambda_{e p}-\mu^{*}\left(1+0.62 \lambda_{e p}\right)}\right]
$$

Where $\mu^{\bullet}$ is the retarded Coulomb potential parameter and $\Theta_{D}$ is the Debye temperature for the characteristic phonon spectrum.

Later McMillan's equation was modified by the introduction of the spin fluctuations effect first numerically [26] and then analytically [27]. The effect of the spin fluctuations on superconductivity arises from the fact that the phonon-mediated electron-electron attraction between two electrons with antiparallel spins in two different bands is screened by the presence of a large number of electrons with parallel spins near one of those two electrons in its band. This screening effect results in a 
decrease in the electron-phonon interaction and therefore depresses the superconductivity. Spin fluctuation effect is more visible in nearly ferromagnetic and enhanced paramagnetic materials where electron spins can align ferromagnetically.

Introducing the spin fluctuations effect into McMillan's equation we obtain after some manipulations the modified McMillan equation:

$$
T_{c} \simeq \frac{\Theta_{D}}{1.45} \exp \left[-\frac{1+\lambda_{e p}+\lambda_{s f}}{\lambda_{e p}-\lambda_{\text {sf }}-\mu^{*}}\right]
$$

where $\lambda_{s f}$, spin fluctuations mass enhancement parameter is given by [28]:

$$
\lambda_{s f}=\frac{9}{2} \bar{I} \ln \left[1+\frac{P_{1}^{2}}{12} \frac{\bar{I}}{(1-\bar{I})}\right]
$$

$P_{1}$ is the momentum cutoff for spin fluctuations expressed as a fraction of the Fermi momentum and barI is the Stoner enhancement factor in the valence magnetic susceptibility given by:

$$
\chi_{v}=\frac{\mu_{B}^{2} N^{b}(0)}{1-\bar{I}}
$$

where $\mu_{B}$ is the Bohr magneton and $\mathrm{N}^{\mathrm{b}}(0)$ is the bare density of electronic states at the Fermi energy. Usually it is difficult to obtain $\mathrm{N}^{\mathrm{b}}(0)$ from simple measurements. In cases where type II superconductors are involved, $\mathrm{N}^{\mathrm{b}}(0)$ can be determined from specific heat density of states $\mathrm{N}^{\gamma}(0)$ obtained from Ginsburg-Landau-Abrikosov-Gorkov theory [29].

$$
\begin{gathered}
N^{\gamma}(0)=-\left.\left(9.45 \times 10^{-10}\right) \frac{M}{\rho d} \frac{d H_{c 2}}{d T}\right|_{T_{c}} \\
N^{b}(0)=\frac{N^{\gamma}(0)}{1+\lambda_{\rho f}+\lambda_{\text {ep }}}
\end{gathered}
$$

$\mathrm{M}$ is the molecular weight in grams, $d$ is the density of the sample in $\mathrm{g} / \mathrm{cm}^{3}, \mathrm{~N}^{\gamma}(0)$ is in states/eV atoms, and $\rho$ is the resistivity at liquid Helium temperature.

As mentioned before, these formulas are obtained for materials with crystalline structure, while amorphous materials do not have a periodic structure. This af- 
fects their electronic and phononic states. In an amorphous metal the electrons are scattered by each atom. This contributes to two major differences in the electronic structure between amorphous and crystalline materials. First, there are no Bragg reflections for electrons and second, electrons have a shorter mean free path in amorphous materials. Consequently all complications which are typical for the crystalline state such as Brillouin zones, bands and holes do not occur in amorphous state. On the other hand the electron momentum will not be a good quantum number. While the loss of Brillouin zones removes lots of complications, the loss of momentum as a good quantum number causes great difficulties [24]. This problem in the electronic structure can be overcomed by applying the Faber-Ziman liquid metal theory of nearly free electrons [30] which has been partially successful in explaining the transport and optical properties of amorphous and liquid simple metals.

In the phonon part, because of the collapse of the lattice structure, there are no quantized lattice vibrations, so it seems that using the name phonon with the usual consept is meaningless. But one also can manage to keep the name phonon in amorphous materials by generalizing its concept from lattice vibrations to both propagating and localized atomic oscillations. With this change all we need is to calculate the Eliashberg function. This was accomplished by Bergman [31], and Poon and Geballe [32] by calculating the Eliashberg function in the low-frequency region where the continuum model for acoustic phonons is valid in terms of material parameters.

$$
\alpha^{2} F(\omega)=\frac{e^{2} E_{f} k_{f}^{2} N(0) \rho}{3 \pi<v^{3}>m M}
$$

where $\left\langle v^{3}\right\rangle$ is the mean cube sound velocity, $m$ is the electronic mass, $E_{f}$ and $k_{f}$ are the Fermi energy and wave vector. With this we can obtain the electron-phonon coupling constant $\lambda$ from formula 3.5. These manipulations allows us to use the usual McMillan equation and other related formulas for analyzing the superconductivity in amorphous materials to the best approximation known up to now. 


\subsection{DSC Measurements Results}

Differential scanning calorimetry (DSC) technique was used as a probe to search and justify the crystallization characteristics of the glassy ribbons. Figures 3.1-3.3 show the DSC thermographs of the samples. Although DSC measurements were done as part of the characterization of the samples, it provides a unique information on the crystallization characteristics of the $\mathrm{Fe}_{\mathrm{x}} \mathrm{Zr}_{100-\mathrm{x}}$ compositions in a wide range $20 \leq x \leq 33$. As we can see from Figure 3.3 the thermographs for $\mathrm{Fe}_{20} \mathrm{Zr}_{80}$ and $\mathrm{Fe}_{21} \mathrm{Z}_{\mathbf{7 9}}$ compositions are different from the other compositions in terms of having two peaks. The presence of the first peak which is relatively small compared to the second one is due to primary crystallization of Zirconium in its high pressure $\omega-\mathrm{Zr}$ structure. The second peak for these two compositions corresponds to a phase which is composed of $\omega-\mathrm{Zr}$ and a new crystalline product, $\mathrm{FeZ}_{\mathrm{r}_{3}}$, with the orthorombic structure. This crystallization pattern was reported previously [17] for $\mathrm{Fe}_{20} \mathrm{Zr}_{80}$ only.

Another interesting observation from the DSC thermographs is the variation of the crystallization temperature $T_{x}$ of the samples with composition. This is shown in Figure 3.4. The crystallization temperature for each sample was determined from the peak position of the corresponding exotherms. The sudden decrease in $T_{x}$ vs composition for Fe20Zr80 and Fe21Zr79 is due to the primary crystallization of $\mathrm{Zr}$ as discussed above. However, as the crystallization process in the compositions with $x>21$ includes the formation of $\mathrm{FeZr}_{3}$, it is more natural, for comparison purposes, to choose the second crystallization peak for $\mathrm{Fe}_{20} \mathrm{Z}_{\mathrm{r}_{80}}$ and $\mathrm{Fe}_{21} \mathrm{Z}_{799}$ as $\mathrm{T}_{\mathbf{x}}$. This produces a minimum in the $\mathrm{T}_{\mathbf{x}}$ vs. composition plot at $\mathrm{Fe}_{23} \mathrm{Z}_{\mathbf{r}_{77}}$, indicating a eutectic at this composition which is consistent with the Iron-Zirconium phase diagram [33]. The smooth variation of $T_{x}$ shows the good quality of the samples. In Figure 3.4 and for other properties from now on, we will use the compositions as determined from the electron microprobe measurements. 


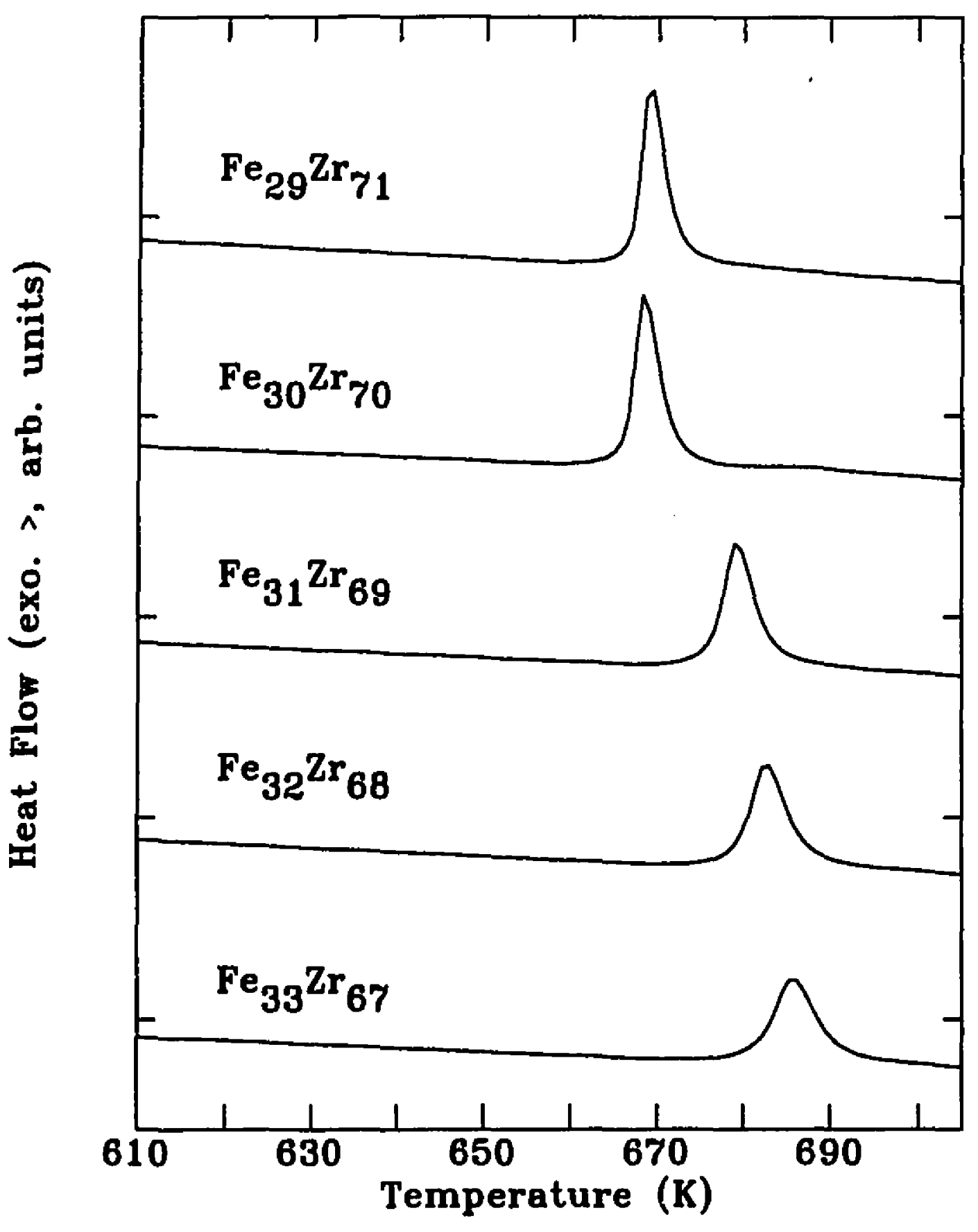

Figure 3.1: DSC thermographs for samples $\mathrm{Fe}_{93} \mathrm{Z}_{67}$ to $\mathrm{Fe}_{28} \mathrm{Z}_{71}$. 


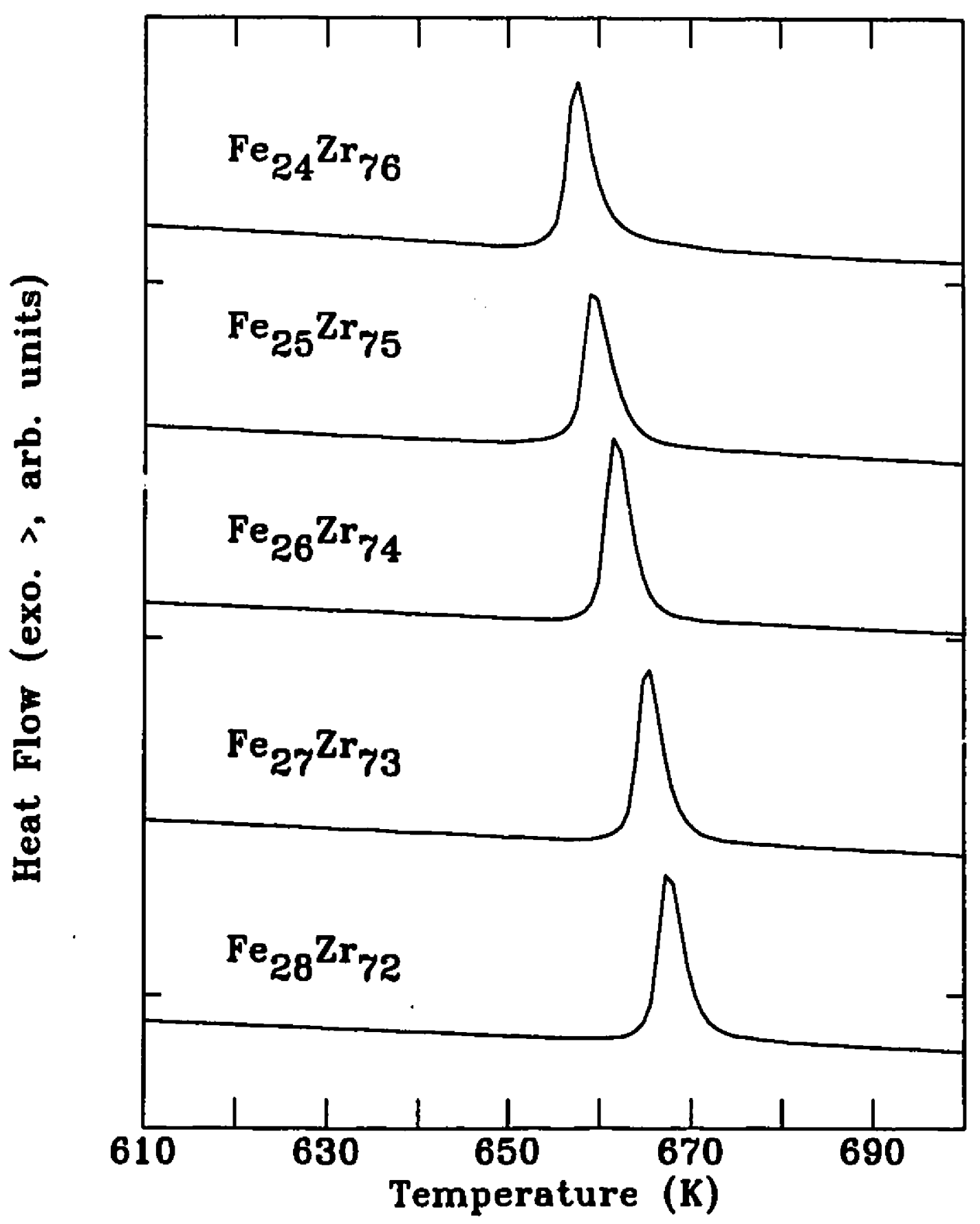

Figure 3.2: DSC thermographs for samples $\mathrm{Fe}_{28} \mathrm{Zr}_{72}$ to $\mathrm{Fe}_{24} \mathrm{Zr}_{78}$. 


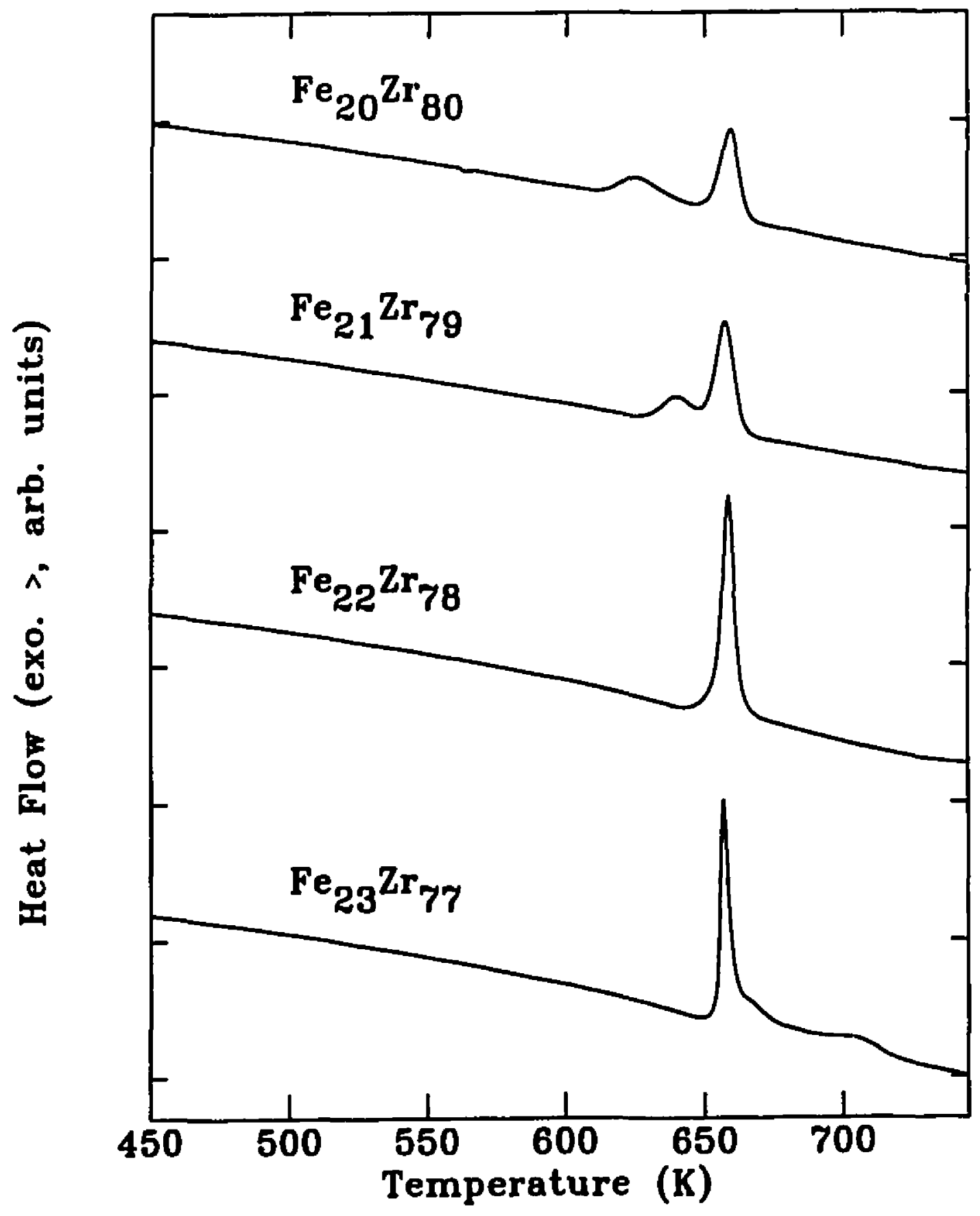

Figure 3.3: DSC thermographs for samples $\mathrm{Fe}_{28} \mathrm{Z}_{77}$ to $\mathrm{Fe}_{20} \mathrm{Z}_{\mathrm{r}_{80}}$. 


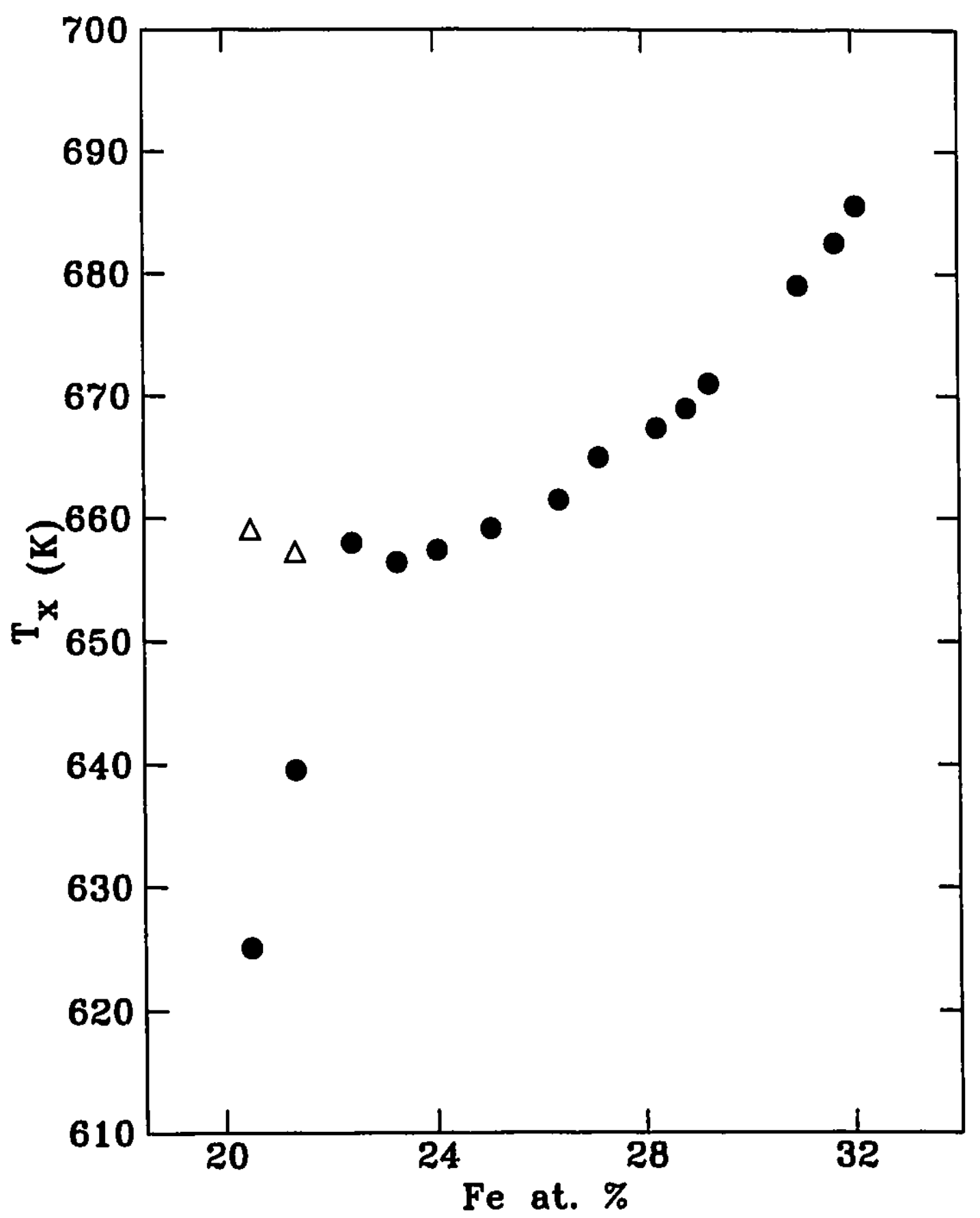

Figure 3.4: Crystallization temperature $\left(T_{x}\right)$ vs. composition. $\Delta$ represents the crystallization temperature obtained from the second peak position of the DSC thermograph for $\mathrm{Fe}_{21} \mathrm{Z}_{79}$ and $\mathrm{Fe}_{20} \mathrm{ZT}_{80}$ compositions. 


\subsection{Room temperature resistivity measurements results}

Room temperature resistivity of the samples was obtained through measuring the room temperature resistance of the ribbons and using the following formula.

$$
\rho=\frac{R M}{d l}
$$

where $M=m / l$ is the mass per unit lengh, $d$ is the density of the sample, 1 is the length of the ribbon between the voltage probes and $R$ is the resistance of the ribbon. Values of the $M, R$, and $\rho$ for each sample are collected in table 3.1. As listed in the table, values of $\rho$ are accurate within $\pm 3 \mu \Omega-\mathrm{cm}$. The major source of error on the resistivity results comes from the error in measuring the density of the ribbons, indicating the non-uniformity of the geometry of the ribbons i.e. variation of the ribbons thickness and width over the length of the ribbons $(70-100 \mathrm{~cm})$. within these errors our resistivity results are in good agreement with those reported in reference [15]. Figure 3.5 shows the variation of the room temperature resistivity of the samples as a function of the measured composition.

As we can see from table 3.1, resistivity increases with the iron content in the compositions. This can be explained by looking at the electronic structure of amorphous Fe-Zr alloys. Photoemission studies $[34,35]$ indicate that the band structure of amorphous binary alloys are constructed from the superposition of the d-bands of the individual constituents. In a recent study on this subject [36] it has been shown that by increasing the iron content in Fe-Zr amorphous alloys, the density of the states at the Fermi level increases. This means that more d-orbitals are at the Fermi level. According to the Mott's s-d scattering model [37] the s or p electrons which carry the current can be scattered from the $d$ holes at the Fermi surface so that the resistivity is proportional to the density of the d-states at Fermi level, $N_{d}\left(E_{f}\right)$. Therefore increasing the iron content increases the density of d-states at Fermi level which leads to an increase in the resistivity of the alloy. 
Table 3.1: Room temperature resistivity measurements results

\begin{tabular}{|c|c|c|c|}
\hline Composition & $\mathrm{M}(\mathrm{g} / \mathrm{cm})$ & $\mathrm{R}(\Omega)$ & $\rho(\mu \Omega-\mathrm{cm})$ \\
\hline $\mathrm{Fe}_{20} \mathrm{Zr}_{80}$ & $9.720 \times 10^{-4}$ & 44.123 & $160 \pm 3$ \\
\hline $\mathrm{Fe}_{21} \mathrm{Z}_{79}$ & $1.176 \times 10^{-3}$ & 40.592 & $161 \pm 3$ \\
\hline $\mathrm{Fe}_{22} \mathrm{Z}_{78}$ & $1.227 \times 10^{-3}$ & 36.268 & $161 \pm 3$ \\
\hline $\mathrm{Fe}_{23} \mathrm{Z}_{77}$ & $1.075 \times 10^{-3}$ & 42.432 & $161 \pm 3$ \\
\hline $\mathrm{Fe}_{24} \mathrm{Z}_{\mathrm{r}_{76}}$ & $1.063 \times 10^{-3}$ & 42.895 & $162 \pm 3$ \\
\hline $\mathrm{Fe}_{25} \mathrm{Z}_{75}$ & $7.410 \times 10^{-4}$ & 62.899 & $163 \pm 3$ \\
\hline $\mathrm{Fe}_{28} \mathrm{Z}_{\mathrm{r}_{74}}$ & $1.012 \times 10^{-3}$ & 46.222 & $164 \pm 3$ \\
\hline $\mathrm{Fe}_{27} \mathrm{Z}_{73}$ & $9.210 \times 10^{-4}$ & 51.085 & $163 \pm 3$ \\
\hline $\mathrm{Fe}_{28} \mathrm{Z}_{72}$ & $1.069 \times 10^{-3}$ & 41.338 & $165 \pm 3$ \\
\hline $\mathrm{Fe}_{28} \mathrm{Z}_{\mathrm{r}_{71}}$ & $9.370 \times 10^{-4}$ & 41.318 & $167 \pm 3$ \\
\hline $\mathrm{Fe}_{30} \mathrm{Z}_{70}$ & $1.788 \times 10^{-3}$ & 26.858 & $164 \pm 3$ \\
\hline $\mathrm{Fe}_{31} \mathrm{Z}_{69}$ & $1.013 \times 10^{-3}$ & 43.934 & $167 \pm 3$ \\
\hline $\mathrm{Fe}_{32} \mathrm{Z}_{68}$ & $9.490 \times 10^{-4}$ & 47.462 & $166 \pm 3$ \\
\hline $\mathrm{Fe}_{33} \mathrm{Zr}_{67}$ & $9.820 \times 10^{-4}$ & 44.357 & $167 \pm 3$ \\
\hline
\end{tabular}




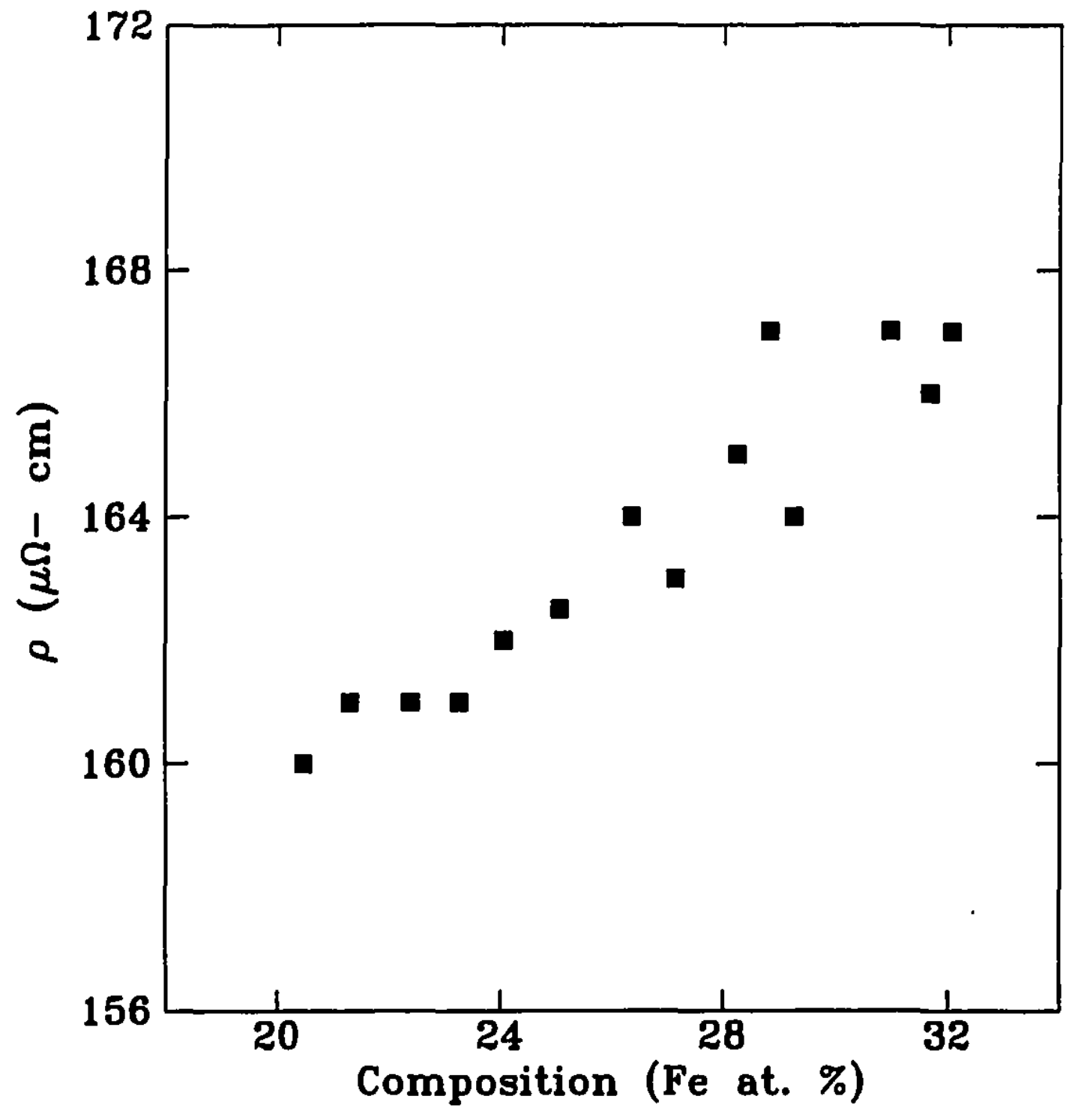

Figure 3.5: Variation of room temperature resistivity with composition (measured) of the samples 


\subsection{SQUID Measurements Results}

\subsection{1 $T_{c}$ Measurements Results}

The purpose of this part of the work was to measure the superconducting transition temperature of both as-made and relaxed samples to determine if there is any increase in $T_{c}$ upon annealing. Basically there are two common methods for measuring $T_{c}$. One is based on the Meissner effect in which when the sample is placed in a magnetic field and when cooled through the transition temperature for superconductivity, the magnetic flux will be expelled from the sample. The other method is based on the fact that for materials capable of having a superconducting state, at a critical temperature $T_{c}$, the sample undergoes a phase transition from a state of normal electrical resistivity to a superconducting state with zero resistivity. Since in the Meissner effect the superconductivity is probed through a bulk property, $\chi$, compared to the resistivity method in which the superconductivity sometimes can be due to a surface effect, i.c. a layer not representative of the bulk, the Meissner effect was prefered.

Using a MPMS Quantum Designe SQUID magnetometer, $T_{c}$ of the samples, asmade and relaxed, were measured through the change in the magnetization of the sample with the variation of magnetic field. Unfortunately since the SQUID magnetometer could not be used for temperatures lower than $1.8 \mathrm{~K}$, we could not measure $T_{c}$ for all the samples with this method. Table 3.2 shows the results of $T_{c}$ measurements at zero magnetic field with an accuracy of order $20 \mathrm{mK}$. Because of certain safety precautions for the SQUID magnetometer, these measurements were carried out at a very small magnetic field, 10 gauss, instead of zero field. This small amount of the magnetic field has a negligble effect on the $T_{c}$ values. It is important to mention that $T_{c}$ was determined from the onset of the decrease in magnetization vs. temperature graph, unlike the usual way in which $\mathbf{T}_{c}$ is obtained from the midpoint of the magnetization vs. temperature transition. The reason for our choice was that for those samples which had a $T_{c}$ close to the lower limit of the temperature range covered by SQUID, $1.8 \mathrm{~K}$, the lower flat part of the graph in the superconducting phase was 
Table 3.2: Results of $T_{c}$ measurements at zero magnetic field with the SQUID magnetometer

\begin{tabular}{|c|c|c|}
\hline \multirow{2}{*}{ compositions } & \multicolumn{2}{|c|}{$T_{c}(\mathrm{~K})$} \\
\cline { 2 - 3 } & As-made & Relaxed \\
\hline $\mathrm{Fe}_{20} \mathrm{Z}_{\mathrm{r}_{80}}$ & 3.08 & 3.30 \\
\hline $\mathrm{Fe}_{21} \mathrm{Z}_{\mathrm{r}_{78}}$ & 2.85 & 3.00 \\
\hline $\mathrm{Fe}_{22} \mathrm{Z}_{78}$ & 2.63 & 2.85 \\
\hline $\mathrm{Fe}_{23} \mathrm{Z}_{\mathrm{r}_{77}}$ & 2.50 & 2.75 \\
\hline $\mathrm{Fe}_{24} \mathrm{Z}_{78}$ & 2.25 & 2.50 \\
\hline $\mathrm{Fe}_{25} \mathrm{Z}_{\mathrm{r}_{75}}$ & - & 2.20 \\
\hline
\end{tabular}

not observable specially for higher fields. In Figure $3.6 T_{c}$ for as-made and relaxed samples is ploted as a function of the measured compositions.

By repeating the $T_{c}$ measurements at four different magnetic fields up to 1 Tesla as described in Chapter 2 , the upper critical field, $\mathbf{H}_{\mathrm{c} 2}$, for those as-made and relaxed samples listed in table 3.2 was obtained. The quantity $\left[\mathrm{dH}_{\mathrm{c} 2} / \mathrm{dT}\right]_{T_{e}}$, needed for the calculations of the specific heat density of states $\mathrm{N}^{\gamma}(0)$, was determined from the slope of the $\mathrm{H}_{\mathrm{c} 2}$ vs. $\mathrm{T}_{\mathrm{c}}$ curve at $\mathrm{T}_{\mathrm{c}}(0)$. A list of $\left[\mathrm{dH}_{\mathrm{c} 2} / \mathrm{dT}\right]_{\mathrm{T}_{\mathrm{c}}}$ results together with the accuracy of each result is given in table 3.3. As we can see from the table the errors are quite large. The major source for these errors comes from the problem that we had in the mounting of our samples in the SQUID magnetometer at Brock University where we had to mount our samples on a straw with silicon grease. Although silicon grease which is a diamagnetic material does not affect our $T_{c}$ values, as mentioned in Chapter 2 , it affects our upper critical field, $\mathrm{H}_{\mathrm{c} 2}$, values. Nevertheless, our $\left[\mathrm{dH}_{\mathrm{c} 2} / \mathrm{dT}\right]_{\mathrm{T}_{\mathrm{e}}}$ values for as-made samples are in close agreement with those reported in previous studies [15] and this gave us confidence to trust our results for further analysis. Inspite of the uncertainty in the absolute values of $\left[\mathrm{dH}_{\mathrm{c} 2} / \mathrm{dT}\right]_{\mathrm{T}_{\mathrm{e}}}$, we cn clearly see the decrease in $\left[\mathrm{dH}_{\mathrm{c} 2} / \mathrm{dT}\right]_{\mathrm{T}_{\mathrm{c}}}$ upon structural relaxation. This implies, from equations 3.10 and 3.11 that $\lambda_{\text {sf }}+\lambda_{\text {ep }}$ decreases upon relaxation. 
Table 3.3: Measured values of $\left.\frac{\mathrm{dH}_{\mathrm{c}} \mathrm{d}}{\mathrm{dT}^{\mathrm{T}}}\right|_{\mathrm{Tc}}(\mathrm{kOe} / \mathrm{K})$

\begin{tabular}{|c|c|c|}
\hline \multirow{2}{*}{ compositions } & \multicolumn{2}{|c|}{$\left.\frac{\mathrm{dH}_{s 2}}{\mathrm{dT}}\right|_{\mathrm{r}_{e}}(\mathrm{kOe} / \mathrm{K})$} \\
\cline { 2 - 3 } & As-made & Relaxed \\
\hline $\mathrm{Fe}_{20} \mathrm{Zr}_{80}$ & $33.8 \pm 8.8$ & $20.0 \pm 4.8$ \\
\hline $\mathrm{Fe}_{21} \mathrm{Zr}_{79}$ & $47.7 \pm 3.1$ & $41.1 \pm 3.3$ \\
\hline $\mathrm{Fe}_{22} \mathrm{Zr}_{78}$ & $41.6 \pm 1.3$ & $42.6 \pm 3.6$ \\
\hline $\mathrm{Fe}_{23} \mathrm{Zr}_{77}$ & $42.6 \pm 2.9$ & $33.5 \pm 3.6$ \\
\hline $\mathrm{Fe}_{24} \mathrm{Zr}_{76}$ & $36.3 \pm 2.8$ & $28.4 \pm 3.0$ \\
\hline $\mathrm{Fe}_{25} \mathrm{Zr}_{75}$ & - & $16.5 \pm 3.4$ \\
\hline
\end{tabular}

\subsubsection{Susceptibility Measurements results}

The magnetic susceptibilities, $\chi$, of three glasses with compositions $\mathrm{Fe}_{30} \mathrm{Z}_{\mathbf{r}_{70}}, \mathrm{Fe}_{24} \mathrm{Zr}_{\mathbf{r}_{76}}$, and $\mathrm{Fe}_{20} \mathrm{Zr}_{80}$ were measured in the as-made and relaxed states. These compositions were selected to cover the range of interest.

For each sample the total paramagnetic suseptibility was calculated from the relation $M=\chi H$ as shown in Figures 3.7-3.9. The data was fitted with a linear least squares fit with an estimated accuracy of the $0.5 \%$. Since the paramagnetic susceptibility of $\mathrm{Fe}_{x} \mathrm{Zr}_{100-x}$ glasses in the range $20 \leq x \leq 33$ is temperature independent [15], all the measurements were carried out at room temperature. In the paramagnetic region, the susceptibility is written [38] as:

$$
\chi=\chi_{v}+\chi_{\text {core }}+\chi_{v v}
$$

where $\chi_{v}$ is the valence (Pauli) susceptibility, $\chi_{\text {core }}$ is the diamagnetic core susceptibility, and $\chi_{v v}$ is the Van Vleck diamagnetic susceptibility which is sometimes necessory to correct for core susceptibility of atoms with unfilled electron shells. Reliable values for the Van Vleck susceptibility are difficult to obtain, since they can not be measured directly. Suitable values for $\chi_{v v}$ for our samples could be estimated 
Table 3.4: Valence susceptibility, $x_{v}$

\begin{tabular}{|c|c|c|}
\hline \multirow{2}{*}{ composition } & \multicolumn{2}{|c|}{$\chi_{v}(\mathrm{emu} / \mathrm{mol}) \pm 0.006 \times 10^{-4}$} \\
\cline { 2 - 3 } & As-made & Relaxed \\
\hline $\mathrm{Fe}_{20} \mathrm{Z}_{80}$ & $1.519 \times 10^{-4}$ & $1.109 \times 10^{-4}$ \\
\hline $\mathrm{Fe}_{24} \mathrm{Z}_{76}$ & $1.673 \times 10^{-4}$ & $1.430 \times 10^{-4}$ \\
\hline $\mathrm{Fe}_{30} \mathrm{Z}_{70}$ & $2.244 \times 10^{-4}$ & $2.184 \times 10^{-4}$ \\
\hline
\end{tabular}

from an analysis of the Knight shift in amorphous $\mathrm{Cu}-\mathrm{Z} \mathbf{r}$, measured by NMR [39]. However these values are prone to errors and can not be verified easily, as there are no accurate values for the Knight shift even for $\mathrm{Cu}$ and $\mathrm{Zr}$ in the literature. Therefore we have decided to ignore the contribution of the Van Vleck susceptibility to the total susceptibility. By using the core susceptibility for iron $\left(-29 \times 10^{-6} \mathrm{emu} / \mathrm{mol}\right)$ and zirconium $\left(-20 \times 10^{-6} \mathrm{emu} / \mathrm{mol}\right)$ [38], and the measured values of the total susceptibility, the valance susceptibility of the three pairs, as-made and relaxed, needed for the analysis was obtained. A list of $\chi_{v}$ for each sample is given in table 3.4. As we can see the valence susceptibility of each sample shows a decrease upon annealing. This decrease in susceptibility increases directly with the zirconium content in the compositions. For example in $\mathrm{Fe}_{30} \mathrm{Z}_{\mathrm{r}_{70}}$, the susceptibility decreases by $2.67 \%$ upon structural relaxation, while the decrease in susceptibility for $\mathrm{Fe}_{24} \mathrm{Z}_{\mathrm{r}_{76}}$, and $\mathrm{Fe}_{20} \mathrm{Z}_{\mathbf{8 0}}$ is, respectively, $14.5 \%$ and $27 \%$. It is important to mention here that the variation of the susceptibility with composition, as shown in Fig. 3.10, shows the expected sharp increase in susceptibility with increasing iron content in the Fe- $\mathrm{Zr}$ compositions $[15,40]$. 


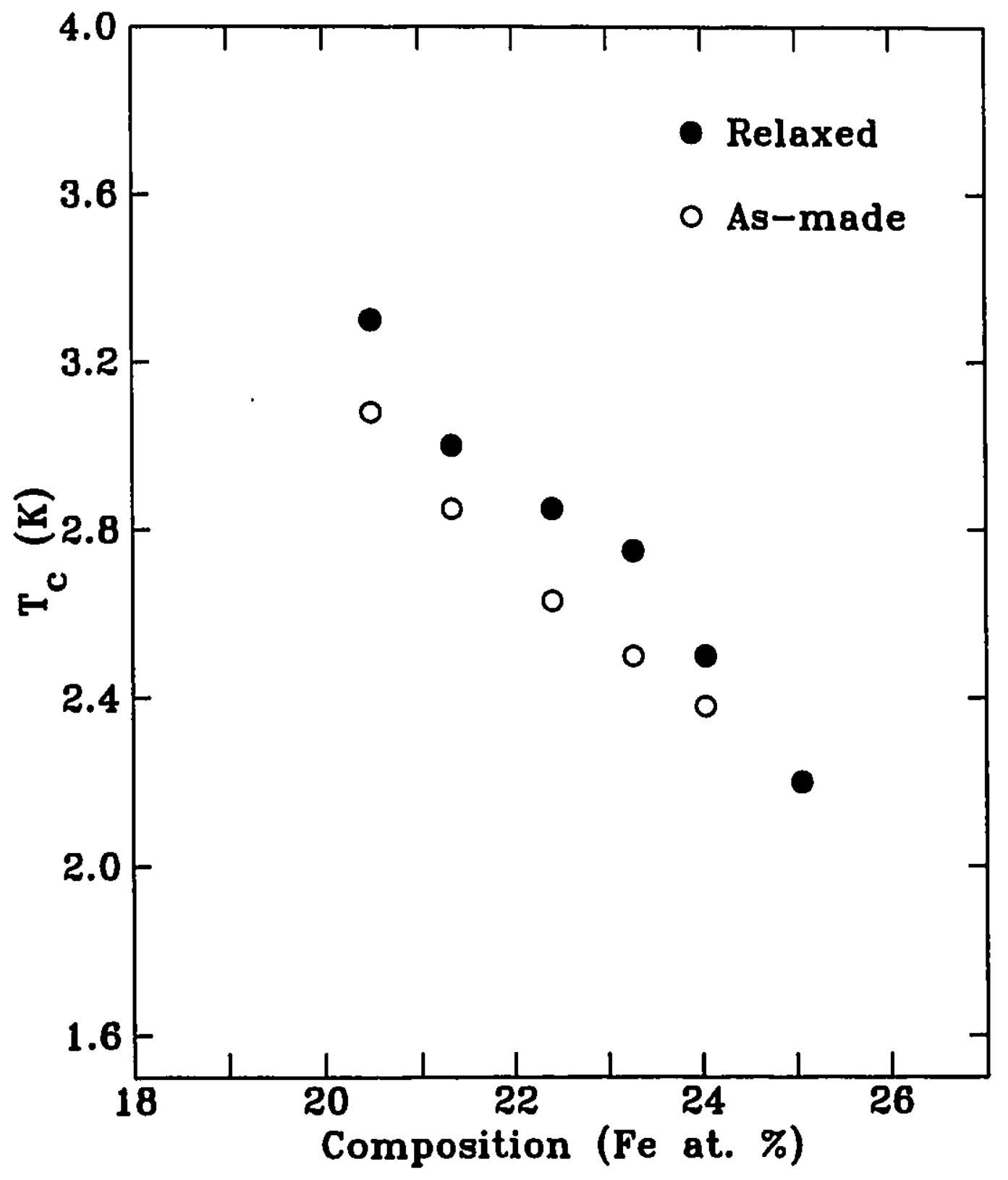

Figure 3.6: Zero field superconducting transition temperature $T_{c}$, vs. composition (measured) for as-made and relaxed samples with accuracy of order $20 \mathrm{mK}$. 


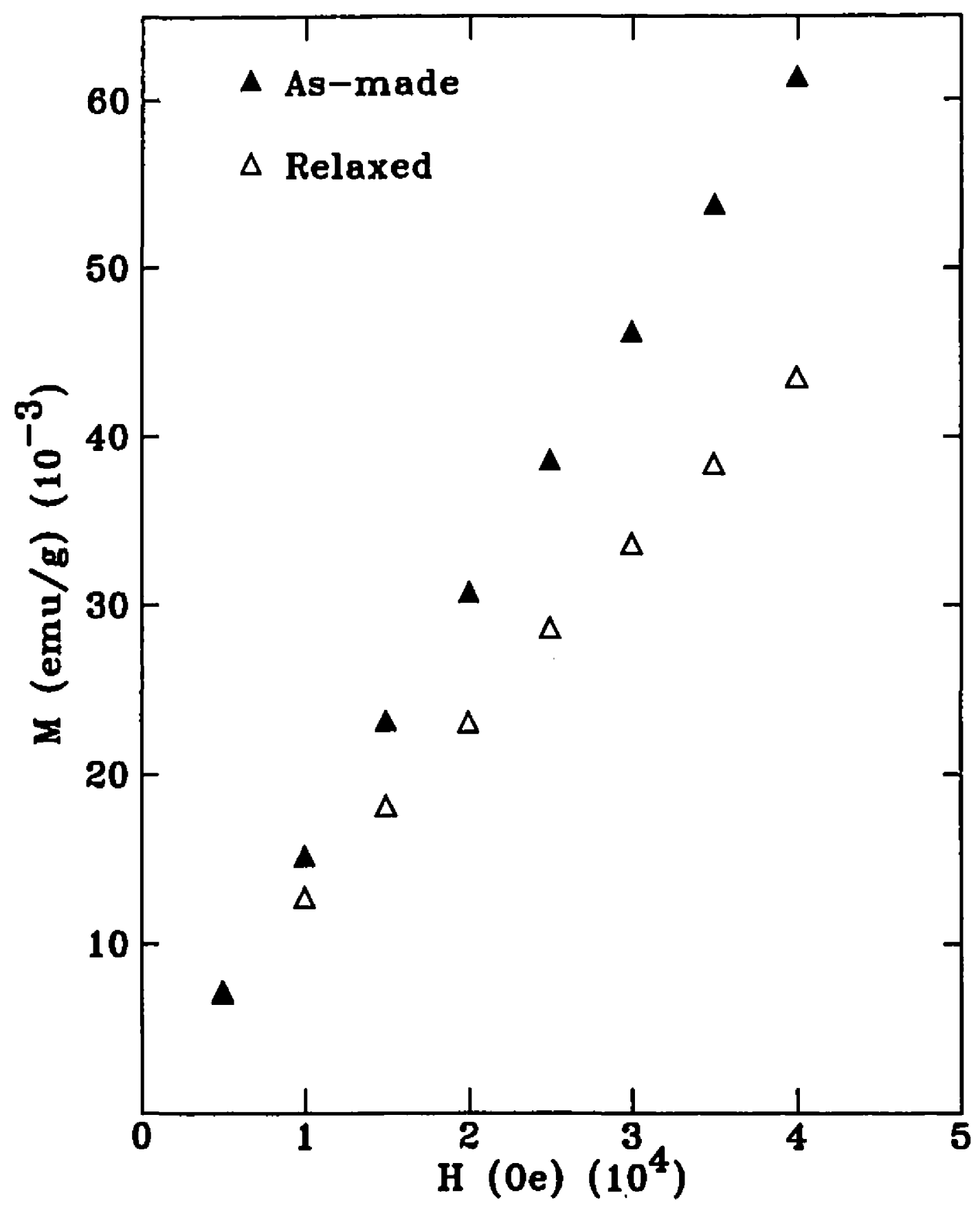

Figure 3.7: $M$ vs. H for as-made ad relaxed Feso Zryo. $M$ is mass normalised. 


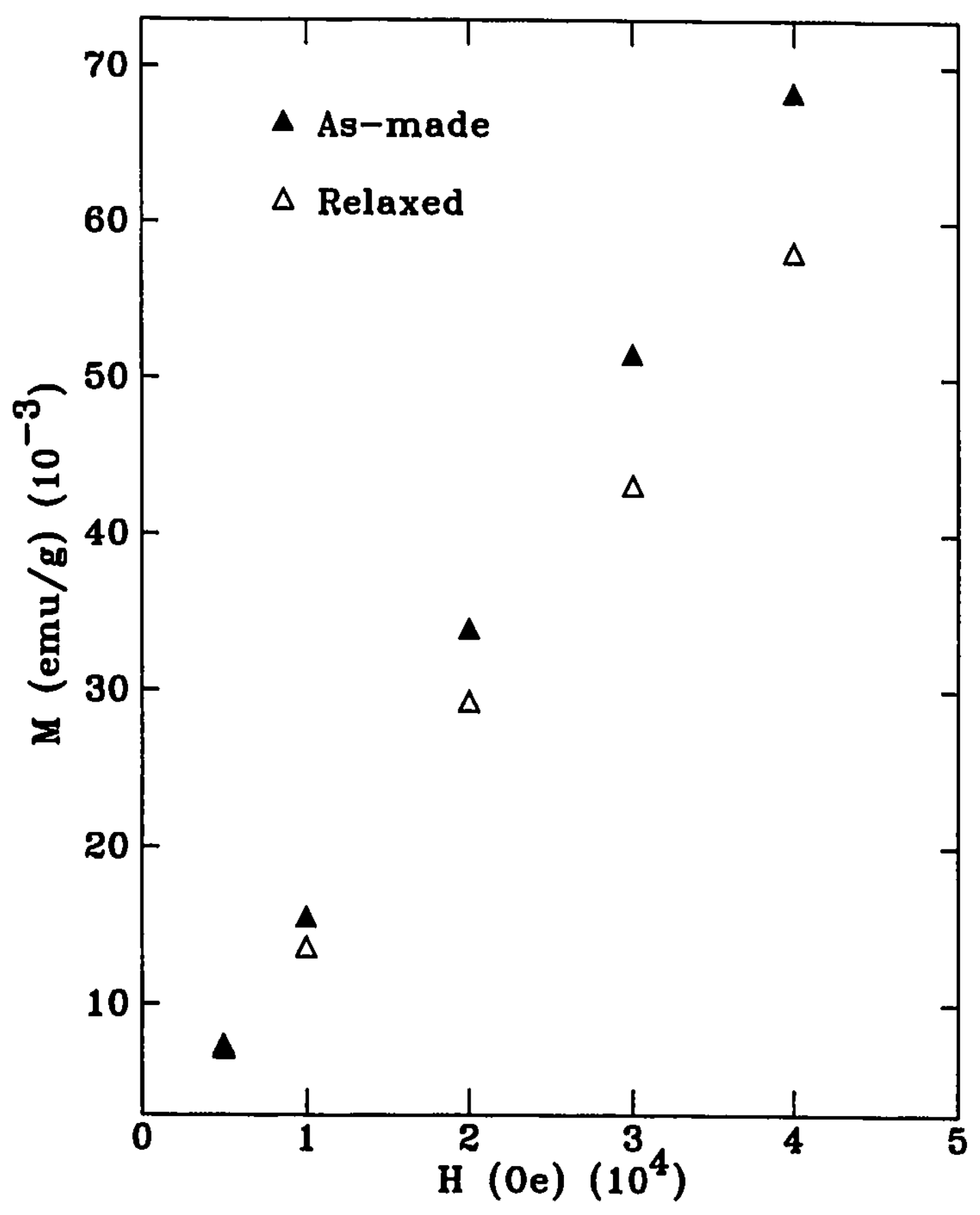

Figure 3.8: $M$ vs. $\mathrm{H}$ for as-made ad relaxed $\mathrm{Fe}_{24} \mathrm{Zr}_{78}$. $\mathrm{M}$ is mass normalized. 


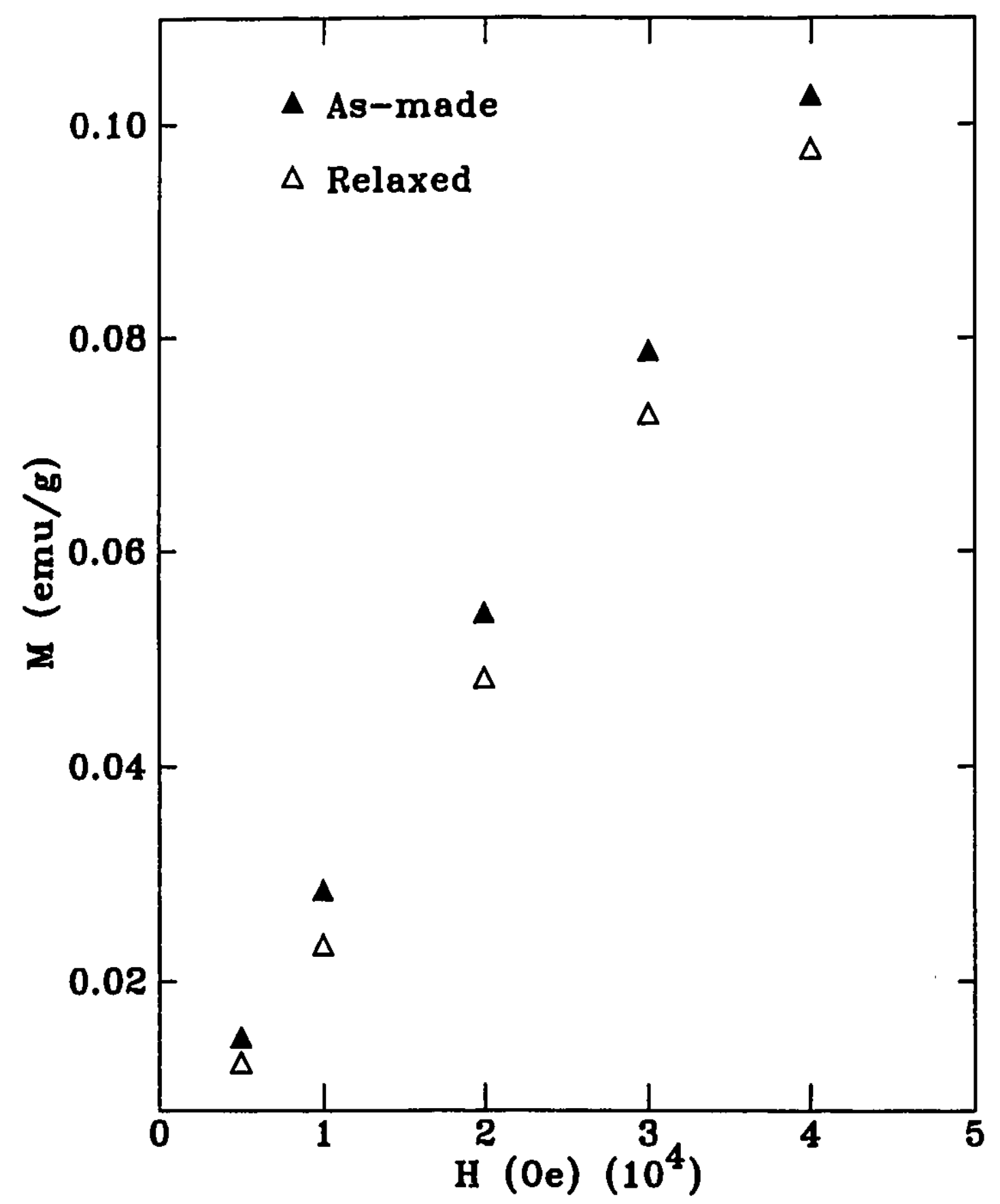

Figure 3.9: $\mathrm{M}$ vs. $\mathrm{H}$ for as-made ad relaxed $\mathrm{Fe}_{20} \mathrm{Z}_{\mathrm{r}_{80}} . \mathrm{M}$ is mass normalized. 


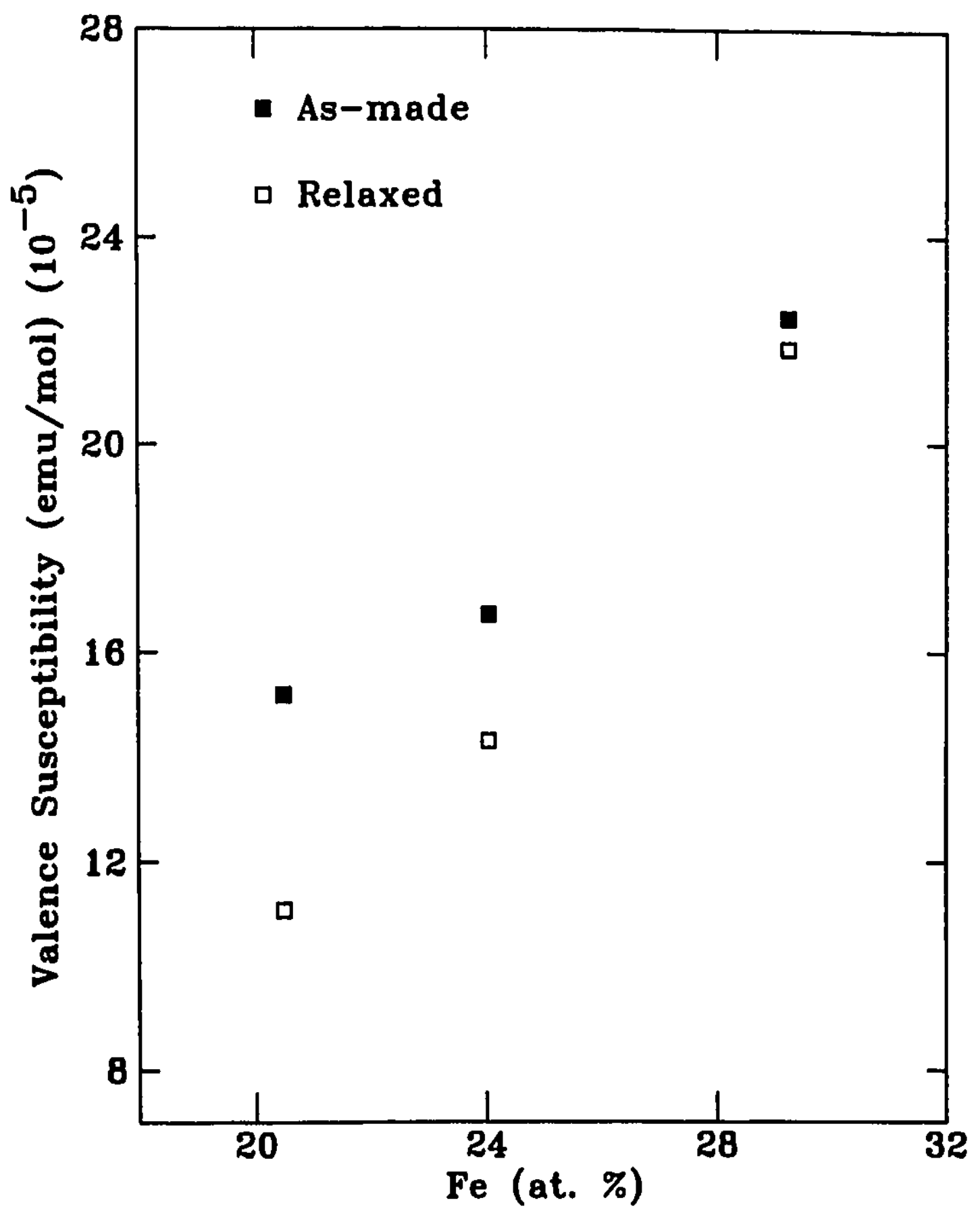

Figure 3.10: Variation of $\chi_{v}$ with composition 


\subsection{Discussion}

In this section we try to give a semi-quantitative explanation for the unusual $T_{c}$ enhancement observed in the Fe- $\mathrm{Zr}$ compositions upon structural relaxation by using the modified form of the McMillan equation which includes the effects of the spin fluctuations, and the theory of superconductivity in metallic glasses which was presented in section 3.1.

Table 3.5: Calculated values of $\bar{I}$ and $\lambda_{\text {, f }}$

\begin{tabular}{|c|c|c|c|c|}
\hline \multirow{2}{*}{ composition } & \multicolumn{2}{|c|}{$\overline{\mathrm{I}}$} & \multicolumn{2}{c|}{$\lambda_{\text {f }}$} \\
\cline { 2 - 5 } & As-made & Relaxed & As-made & Relaxed \\
\hline $\mathrm{Fe}_{20} \mathrm{Zr}_{80}$ & 0.69 & 0.57 & 0.09 & 0.05 \\
\hline $\mathrm{Fe}_{24} \mathrm{Zr}_{78}$ & 0.74 & 0.70 & 0.13 & 0.10 \\
\hline $\mathrm{Fe}_{30} \mathrm{Z}_{70}$ & 0.824 & 0.820 & 0.234 & 0.226 \\
\hline
\end{tabular}

As mentioned earlier in this chapter, the results of our $T_{c}$ measurements showed an increase of about $10 \%$ in superconducting transition temperature of $\mathrm{Fe}-\mathrm{Zr}$ glasses upon structural relaxation. We believe that this unusual increase in $T_{c}$ is due to the presence of spin fluctuations. To prove this point, using equation 3.8 and 3.9 and the measured values of the suscepibility listed in table 3.4 together with the values of the bare density of states, $\mathrm{N}^{\mathrm{b}}(0)$, from ref. [38] we calculated the corresponding values of the Stoner enhancement factor, $\overline{\mathrm{I}}$, and the spin fluctuations mass enhancement parameter,$\lambda_{\text {sf }}$. Recent studies on structural relaxation [41] show that the change in the density of $\mathrm{Zr}$-based metallic glasses is very small (less than $0.2 \%$ ). Therefore we have assumed, in the calculation of the Stoner enhancement factor, that the bare density of states does not change upon annealing. Table 3.5 gives the values for $\overline{\mathrm{I}}$, and $\lambda_{\rho f}$ for three pairs of as-made and relaxed samples. Two important features in table 3.5 should be noted. First is the decrease in both $\bar{I}$ and $\lambda_{\text {sf }}$ upon relaxation, and second is the correlation between the magnitude of the decrease in $\overline{\mathrm{I}}$ and $\lambda_{\text {sf }}$ with increasing the zirconium content in the glass. For example $\lambda_{\text {of }}$ in $\mathrm{Fe}_{50} \mathrm{Z}_{\mathrm{r}_{70}}$ shows 
$3.4 \%$ decrease with relaxation while $\lambda_{8 f}$ in $\mathrm{Fe}_{24} \mathrm{Z}_{76}$ and $\mathrm{Fe}_{20} \mathrm{Zr}_{80}$ drops, respectively, to $23.1 \%$ and $44.4 \%$ with structural relaxation. On the other hand as mentioned in Chapter 1 , structural relaxation decreases the electron-phonon coupling constant, $\lambda_{\text {ep }}$. The measured values of $\left[\mathrm{dH}_{\mathrm{c} 2} / \mathrm{dT}\right]_{\mathrm{T}_{\mathrm{e}}}$ did show a decrease in $\lambda_{\mathrm{Lf}}+\lambda_{\mathrm{ep}}$, but because of the uncertainty in the measurements we were not able to obtain quantitative values for $\lambda_{\text {ep }}$. However, as the $\mathrm{Cu}-\mathrm{Zr}$ metallic glasses are somewhat similar to $\mathrm{Fe}-\mathrm{Zr}$ metallic glasses we can estimate the decrease in $\lambda_{\text {ep }}$ of our compositions from the available data in the literature for $\mathrm{Cu}-\mathrm{Zr}$ compositions. Previous studies [13] show that in the zirconium rich region of $\mathrm{Cu}-\mathrm{Zr}$ the decrease in $\lambda_{\text {ep }}$ upon irreversible structural relaxation is around $3 \%$. Assuming the same amount of decrease in the elctronphonon coupling constant, $\lambda_{\text {ep }}$, for our $\mathrm{Zr}$-rich iron-zirconium compositions we see that the structural relaxation lowers both $\lambda_{\rho f}$ and $\lambda_{e p}$. The data in table 3.1 show that in the $\mathrm{Zr}$-rich region the decrease in $\lambda_{\text {of }}$ is dominant, at least $23 \%$ decrease in $\lambda_{\text {sf }}$ compared to a $3 \%$ decrease in $\lambda_{\text {ep }}$.

Superconducting transition temperature, $T_{c}$, were obtained from the modified form of the McMillan equation, equation 3.7, and a series of generated data in the desired range. $\mu^{*}$ was set to the value 0.13 which is consistent for all $4 \mathrm{~d}$ superconductors. The momentum cutoff factor for spin fluctuations, $P_{1}^{2}$ was taken as $1 / 6$. This value which is not an experimental quantity, is chosen so that consistent values are obtained for zirconium-based systems [15]. Values of $\Theta_{D}$ in $\mathrm{K}$, which are temperature independent, were obtained from a linear fit of the measured values in ref. [40]:

$$
\Theta_{D}=x+172
$$

where $x$ is the iron content in at. \%. As shown in Fig. 3.11, a decrease in $\lambda_{\text {ep }}$ will decrease $\mathrm{T}_{c}$, whereas a decrease in $\lambda_{\text {sf }}$ increases $\mathrm{T}_{c}$, Fig.3.12. Therefore, in iron-zirconium compositions because of the presence of spin fluctuations, structural relaxation results in an increase in $\mathrm{T}_{\mathrm{c}}$, while for other amorphous materials like $\mathrm{Cu}$ $\mathrm{Zr}, \mathrm{Ni}-\mathrm{Zr}, \mathrm{Co}-\mathrm{Zr}, \ldots$...tc. where spin fluctuations are not present, structural relaxation only induces a decrease in $\lambda_{\text {ep }}$, resulting in a decrease in $T_{c}$. 


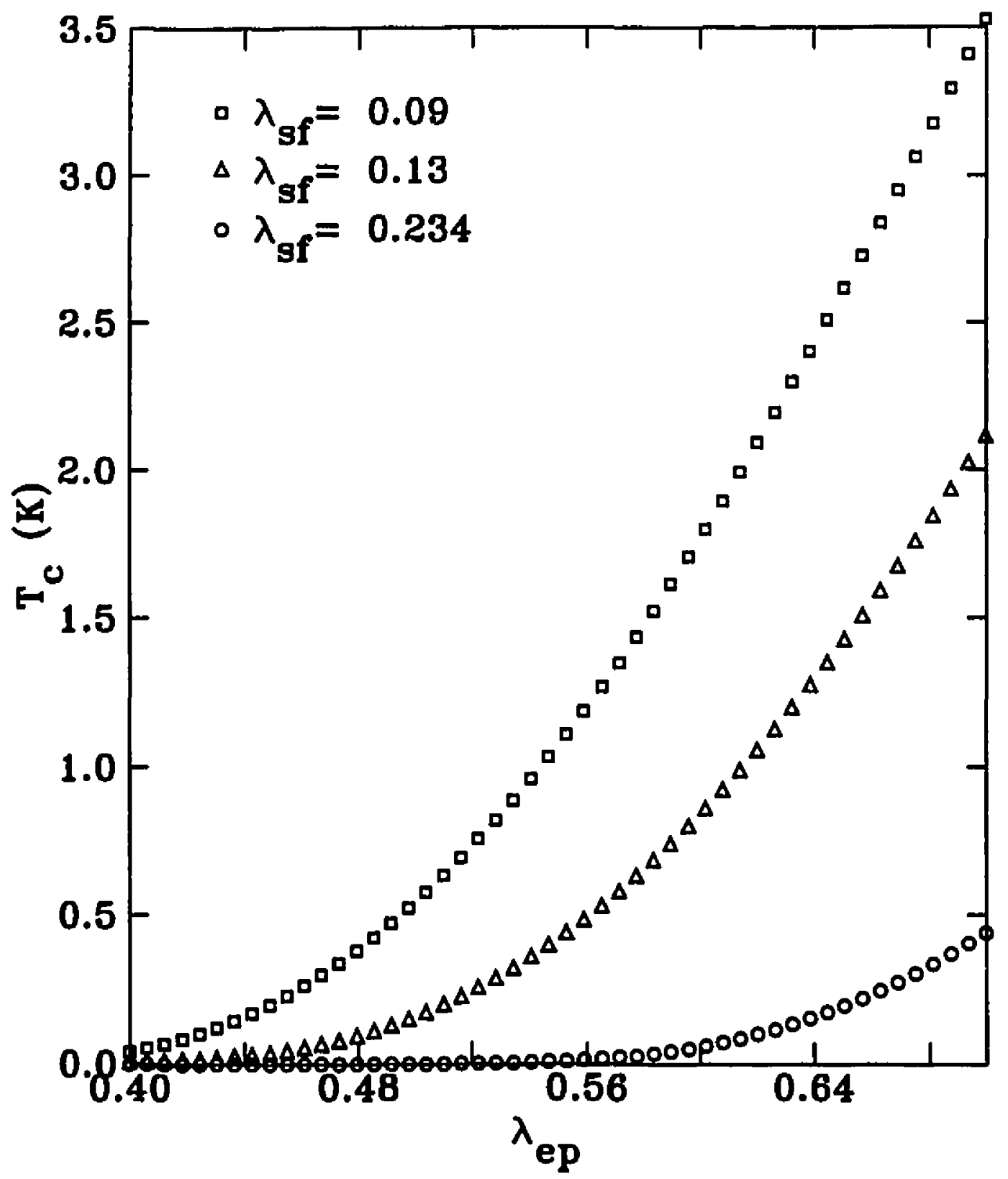

Figure 3.11: Typical variation of $T_{e}$ with $\lambda_{e p}$ for values of $\lambda_{s f}$ corresponding to Fego $\mathrm{Z}_{80}(\square)$, $\mathrm{Fe}_{24} \mathrm{Zr}_{78}(\Delta)$ and $\mathrm{Fe}_{30} \mathrm{Z}_{70}(\mathrm{O})$ 


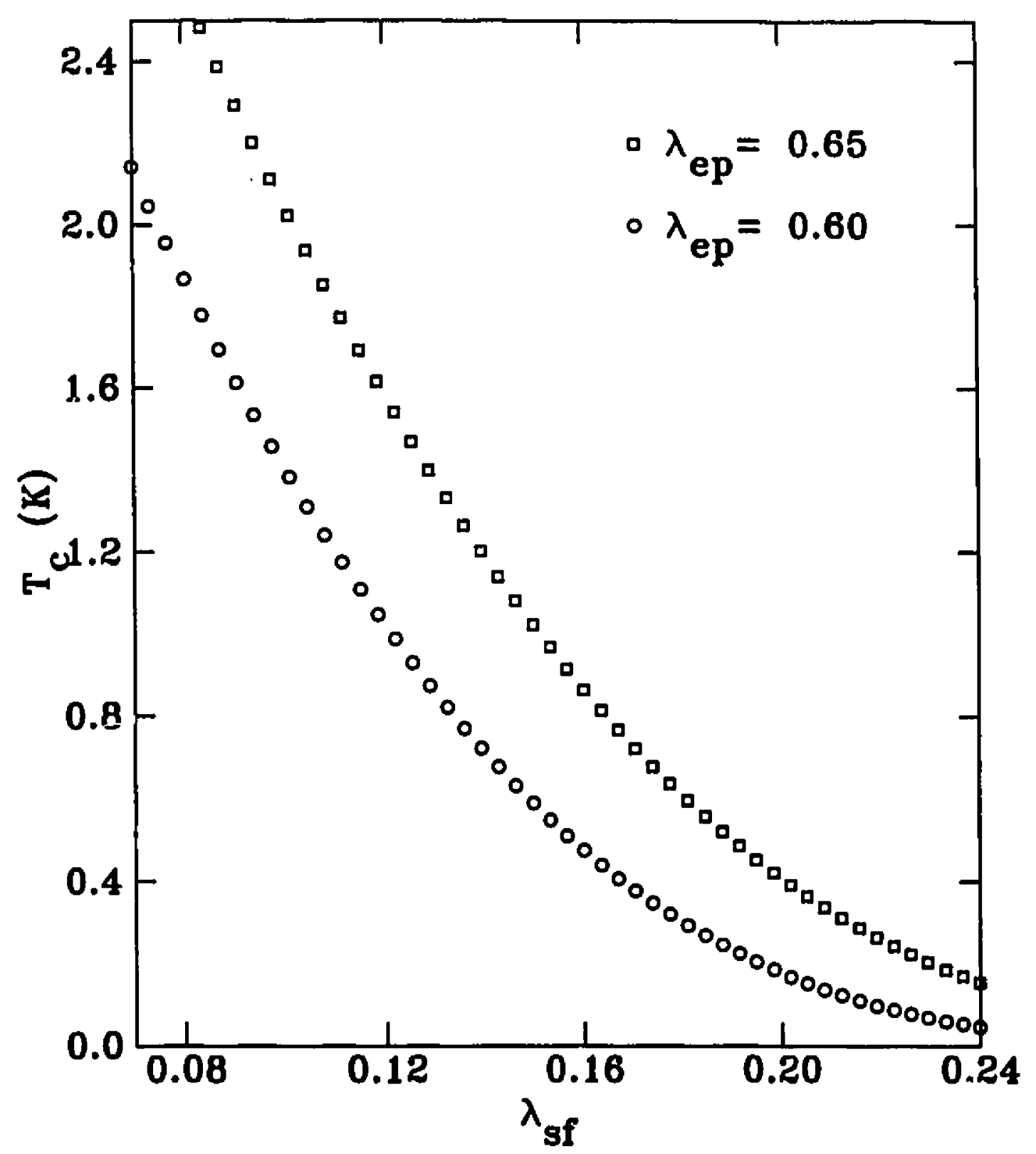

Figure 3.12: Typical variation of $T_{e}$ with $\lambda_{\text {\& }}$ for values of $\lambda_{e p}$ corresponding to $F e_{20} Z_{r_{80}}(\square)$ and $\mathrm{Fe}_{\text {so }} \mathbf{Z}_{\text {ro }}(\mathrm{O})$ 


\section{Chapter 4}

\section{Conclusions}

In this thesis, the effect of irreversible structural relaxation on the superconducting transition temperature, $T_{c}$, of iron-zirconium metallic glasses was studied. We have shown that in this system, unlike other metallic glass systems, $T_{c}$, increases upon structural relaxation. By introducing the modified theory of superconductivity in amorphous materials which includes the effect of spin fluctuations, we have provided a theoretical basis for this $T_{c}$ enhancement. Moreover by measuring the susceptibility, $\chi$, and the upper critical field, $\mathrm{H}_{\mathrm{c} 2}$, of both as-made and relaxed samples we have provided a semi-quantitative support to our theoretical explanation for this phenomena. The main results of this work are summarized as follows.

$\mathrm{X}$-ray diffractometry and differential scanning calorimetry measurements on each sample showed the homogeneity and excellent quality of the glassy samples. Moreover, electron microprobe measurements showed that the composition of each sample is in good agreement with the corresponding nominal values within \pm 0.5 at. $\%$.

Using the Meissner effect, $T_{c}$ was obtained from the sudden change in magnetization of the samples as a function of temperature. $T_{c}$ measurements on the as-made and relaxed glassy ribbons of $\mathrm{Fe}_{\mathrm{x}} \mathrm{Zr}_{100-\mathrm{x}}$ in the range $20 \leq x \leq 25$ showed an increase of about $10 \%$ in superconducting transition temperature upon irreversible structural relaxation.

By repeating the $T_{c}$ measurements at four different magnetic fields the upper 
critical field, $\mathrm{H}_{\mathrm{c2}}$, was measured. The data showed that the quantity $\left[\mathrm{dH}_{\mathrm{c} 2} / \mathrm{dT}\right]_{\mathrm{T}_{\mathrm{e}}}$, which is related to $\lambda_{\text {ep }}+\lambda_{\text {sf }}$ decreases upon relaxation.

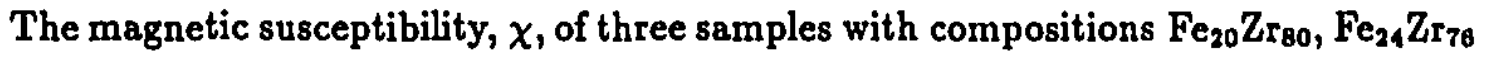
and $\mathrm{Fe}_{30} \mathrm{Zr}_{70}$ in the as-made and relaxed states was measured to examine the presence of the spin fluctuations and their contributions to the observed $\mathrm{T}_{\mathrm{c}}$ enhancement. Valence susceptibility, $\chi_{v}$, was calculated from the measured total susceptibility, $\chi$, by correcting for the diamagnetic core susceptibility. The results showed a decrease in $\chi_{v}$ ranging from $2.67 \%$ for $\mathrm{Fe}_{30} \mathrm{Z}_{\mathrm{r}_{70}}$ to $27 \%$ for $\mathrm{Fe}_{20} \mathrm{Z}_{\mathbf{r}_{80}}$.

By using the relation between spin fluctuations mass enhancement parameter, $\lambda_{0} f$, and the expression for the Stoner enhanced magnetic susceptibility $\overline{\mathbf{I}}$ together with the calculated values of the valence susceptibility, the corresponding values of $\lambda_{\text {s } f}$ for the pair of as-made and relaxed samples, mentioned above, were calculated. The results of these calculations showed a decrease of at least $23 \%$ in $i_{\text {sf }}$ upon structural relaxation in the $\mathrm{Zr}$-rich region of compositions. On the other hand, as mentioned in the text, the decrease in the electron-phonon coupling constant, $\lambda_{e p}$, upon relaxation in that region is less than $3 \%$. This shows that, although structural relaxation causes a decrease in both $\lambda_{\text {of }}$ and $\lambda_{e p}$, the decrease in $\lambda_{, f}$ is dominant ( $\sim 8$ times larger ).

An analysis of the variation of $\mathrm{T}_{\mathrm{c}}$ with $\lambda_{\rho f}$ and $\lambda_{\text {ep }}$ through the modified form of the McMillan equation showed that a decrease in $\lambda_{e p}$ will decrease $\mathrm{T}_{c}$ whereas a decrease in $\lambda_{\text {\&f }}$ increases $\mathrm{T}_{c}$. This analysis together with the dramatic decrease in $\lambda_{\& s}$ compared to that of $\lambda_{\text {ep }}$ upon structural relaxation explains the unique and unusual $\mathrm{T}_{\mathrm{c}}$ enhancement observed in $\mathrm{Zr}$-rich Fe-Zr metallic glasses.

An extension to this work would be to study the effect of irreversible structural relaxation on superconducting transition temperature, $\mathrm{T}_{c}$, in a ternary system like $\left(\mathrm{Fe}_{\mathbf{x}} \mathrm{Ni}_{1-x}\right)_{25} \mathrm{Zr}_{75}$ in which spin fluctuations are present. The Fe-Ni-Zr ternary glasses are an ideal system to test spin fluctuations effect, since the sizes of Fe and $\mathrm{Ni}$ atoms are identical and the glassy alloys have similar structures. As all the compositions have the same structure, the electron-phonon coupling constant, $\lambda_{\text {ep }}$, is therefore not expected to change with the Fe content, $x$. However, it has been shown that the 
effects of spin fluctuations are strongly dependent on Fe content [42]. This glassy system will provide an ideal opportunity to investigate, in detail, the role of $\lambda_{e p}$ and $\lambda_{\text {sf }}$ in the superconductivity of metallic glasses. Another extension to this work would be to study the effect of reversible structural relaxation with different annealing times to see how it affects the $\mathrm{T}_{c}$ in this system. Similar investigations in other metallic glasses where spin fluctuations are present can result in a better understanding of superconductivity in amorphous materials. 


\section{References}

[1] R. Zallen, The Physiscs of Amorphous Solids, (John Wiley \& Sons, Inc. New York), 1983.

[2] M. R. Hore, J. Non-Cryst. Solids, 31, 157(1978).

[3] H. S. Chen, L. C. Kimerling, J. M. Poate, W. L. Brown, Appl. Phys. Lett. 32 , 461 (1978).

[4] A. I. Taub, F. Spaepen, Acta metall., 28, 1781 (1980); A. I. Taub, and F. E. Luborsky, Acta metall., 29, 1939(1981).

[5] H. S. Chen, Mater. Sci. Engng. 26, 79 (1976).

[6] F. E. Luborsky, American Institute of Physics Conf. Proc. 29, 209 (1976).

[7] H. S. Chen, J. Appl. Phys. 49, 3289 (1978).

[8] A. J. Drehman, W. L. Johnson, Phys. Status. Solidi,(a) 52, 499 (1979).

[9] S. J. Poon, Phys. Rev. B 27, 5519 (1983).

[10] R. E. Elmquest, S. J. Poon, Solid State Comm. 41, 221 (1982).

[11] R. Esquinazi, M. E. de la cruz, F. de la cruz, Physica, (B+C) 108, 1215 (1981).

[12] C. C. Tsueli, Appl. Phys. Lett. 33, 262 (1978).

[13] Z. Altounian, T. Guo-hua, J. O. Strom-Olsen, Solid State Comm. 40, 221 (1981).

[14] Z. Altounian unpublished.

[15] Z. Altounian, J. O. Strom-Olsen, Phys. Rev. B 27, 4149 (1983).

[16] E. Abrahams, P. W. Anderson, D. C. Licciardello and T. V. Ramakrishnan, Phys. Rev. Lett. 42, 673 (1979).

[17] Z. Altounian, C. A. Volkert, and J. O. Strom-Olsen, J. Appl. Phys. 57 (6), 1777 (1985).

[18] R. D. Barnard, Thermoelectricity in Metals and Alloys, Taylor \& Francis Ltd., London, 1972.

[19] W. Buckel, R. Hilsch, Z. Phys., 138, 109 (1954); 138, 118 (954).

[20] M. M. Collver, and R. H. Hammond Phys. Rev. Lett. 30, 92 (1973).

[21] L. P. Gor'kov, Zh. Eksperim. i.Theor. Fiz. 36, 1918 (1959). Eng. transl. : Soviet Phys. -JETP 9, 1364 (1959).

[22] E. Domb, W. L. Johnson, J. Low temp. Phys. 33, 29 (1978); R. Koepke, G. Bergmann, Solid State Comm. 19, 435 (1976).

[23] J. Bardeen, L. N. Cooper, J. R. Schreiffer, Phys. Rev. 106, 162 (1957); 108, 1175 (1957). 
[24] G. Bergmann, Physics Reports (Section C of Physics Letters) 27, No. 4 (1976) 159-185. North-Holland.

[25] W. L. McMillan, Phys. Rev. 167, 331 (1968).

[26] N. F. Berk, J. R. Schrieffer, Phys. Rev. Lett. 17, 433 (1966); M. A. Jensen, K. Andres, Phys. Rev. 165, 545 (1968).

[27] J. M. Daams, B. Mitrovic, J. P. Carbotte, Phys. Rev. Lett. 46, 65 (1981).

[28] S. Doniach and S. Engelsberg, Phys. Rev. Lett. 17, 250 (1966); J. R. Schrieffer, J. Appl. Phys. 39, 642 (1968).

[29] T. P. Orlando, E. J. McNiff, Jr., S. Foner, and M. R. Beasely, Phys. Rev. B 19,4545 (1979).

[30] T. E. Faber, and J. Ziman, Phil. Mag., 11, 153 (1965).

[31] G. Bergmann, Phys. Rev. B 23, 5834 (1981).

[32] S. J. Poon, and T. H. Geballe, Phys. Rev. B 18, 233 (1978).

[33] D. Arias and J. P. Abriata, Bulletin of Alloy Phase Diagrams 9, 597 (1988).

[34] P. Oelhafen, E. Hauser and H. Güntherodt, Solid State Comm. 35, 1017 (1980).

[35] A. Amamou, W. L. Johnson, Solid State Comm. 35, 765 (1981).

[36] A. Cossy-Faver, H. -G. Boyen, P. Oelhafen, I. Turek, and J. Hafner, J. of Non-Crystalline Solids 156-158 (1993) 246-250 North-H0land.

[37] N. F. Mott, Phil. Mag., 26, 1249 (1972).

[38] E. Batalla, Z. Altounian, and J. O. Strom-Olsen, Phys. Rev. B 31, 577 (1985).

[39] H. -J. Eifert, B. Elschner, K. H. J. Buschow, Phys. Rev. B 25, 7441 (1982).

[40] A. L. Dawson, Ph.D thesis, McGill University, Montreal, Canada, 1994.

[41] M. Mao, Ph.D thesis, McGill University, Montreal, Canada, 1993.

[42] Z. Altounian, S. V. Dantu, and M. Dikeakos, Phys. Rev. B 49, 8621 (1994). 